\title{
Reciprocal Changes in Voltage-Gated Potassium and Subthreshold Inward Currents Help Maintain Firing Dynamics of AVPV Kisspeptin Neurons during the Estrous Cycle
}

\author{
ㄱ. J. Rudolph Starrett, ${ }^{1}$ R. R. Anthony DeFazio, ${ }^{1}$ and ${ }^{-S}$ Suzanne M. Moenter ${ }^{1,2,3}$
}

https://doi.org/10.1523/ENEURO.0324-21.2021

${ }^{1}$ Department of Molecular and Integrative Physiology, University of Michigan, Ann Arbor, MI 48109, ${ }^{2}$ Department of Obstetrics and Gynecology, University of Michigan, Ann Arbor, MI 48109, and ${ }^{3}$ Department of Internal Medicine, University of Michigan, Ann Arbor, MI 48109

\begin{abstract}
Kisspeptin-expressing neurons in the anteroventral-periventricular nucleus (AVPV) are part of a neural circuit generating the gonadotropin-releasing hormone $(\mathrm{GnRH})$ surge. This process is estradiol-dependent and occurs on the afternoon of proestrus in female mice. On proestrus, AVPV kisspeptin neurons express more kisspeptin and exhibit higher frequency action potentials and burst firing compared with diestrus, which is characterized by a pulsatile rather than a prolonged surge of $\mathrm{GnRH}$ secretion. We hypothesized changes in voltage-gated potassium conductances shape activity profiles of these cells in a cycle-dependent manner. Whole-cell voltage-clamp recordings of GFP-identified AVPV kisspeptin neurons in brain slices from diestrous and proestrous mice revealed three subcomponents of the voltage-sensitive $\mathrm{K}^{+}$current: fast-transient slow-transient, and residual. During proestrus, the $\mathrm{V}_{50}$ of inactivation of the fast-transient current was depolarized and the amplitude of the slow-transient component was reduced compared with diestrus; the residual component was consistent across both stages. Computational models were fit to experimental data, including published estrous-cycle effects on other voltage-gated currents. Computer simulations suggest proestrus-typical $\mathrm{K}^{+}$currents are suppressive compared with diestrus. Interestingly, larger T-type, persistent-sodium, and hyperpolarization-activated currents during proestrus compensate for this suppressive effect while also enabling postinhibitory rebound bursting. These findings suggest modulation of voltage-gated $\mathrm{K}^{+}$and multiple subthreshold depolarizing currents across the negative to positive feedback transition maintain AVPV kisspeptin neuron excitability in response to depolarizing stimuli. These changes also enable firing in response to
\end{abstract}

\section{Significance Statement}

Gonadotropin-releasing hormone $(\mathrm{GnRH})$ neurons provide the central signal to initiate ovulation by releasing a surge of hormone. GnRH neurons are regulated by other cells including those expressing kisspeptin, a potent stimulator of $\mathrm{GnRH}$ secretion. Kisspeptin neurons in the anteroventral-periventricular nucleus (AVPV) express more kisspeptin and become more active during the afternoon of proestrus, the phase of the rodent estrous (reproductive) cycle when the GnRH surge occurs. We found voltage-dependent potassium currents in AVPV kisspeptin neurons change with phase of the estrous cycle. Firing simulations indicated these changes are suppressive if occurring in isolation. But proestrous-typical increases in subthreshold depolarizing currents overcome this suppression and promote greater excitability by increasing rebound firing, possibly contributing to the preovulatory activation of this system. 
hyperpolarization, providing a net increase in neuronal excitability, which may contribute to activation of this population leading up to the preovulatory $\mathrm{GnRH}$ surge.

\section{Key words: AVPV; estrous cycle; excitability; kisspeptin; positive feedback; potassium}

\section{Introduction}

The anteroventral-periventricular (AVPV) nucleus is a critical site involved in the regulation of female fertility, specifically the control of the estradiol-dependent process of ovulation (Kalra and McCann, 1975; Goodman, 1978; Wiegand and Terasawa, 1982; Petersen and Barraclough, 1989; Petersen et al., 1989). The AVPV contains neurons that express both estrogen receptor (ER) $\alpha$ and kisspeptin (Simerly, 1998; Smith et al., 2005), a neuropeptide that acts at gonadotropin-releasing hormone $(\mathrm{GnRH})$ neurons to potently induce $\mathrm{GnRH}$ neuron activity and hormone secretion (Han et al., 2005; Messager et al., 2005; Pielecka-Fortuna et al., 2008; Zhang et al., 2008; Caraty et al., 2013). Ovulation is initiated by positive feedback actions of estradiol at the central and pituitary levels (Döcke and Dörner, 1965; Sarkar et al., 1976; Moenter et al., 1991). In a prevailing theory, sustained elevation of circulating estradiol during the late follicular phase (the cycle day of proestrus in rodents) exerts positive feedback effects via $\mathrm{ER} \alpha$ that drive increased kisspeptin expression in AVPV neurons (Smith et al., 2005; Gottsch et al., 2006; Oakley et al., 2009). Action potential firing by AVPV kisspeptin neurons is also increased on proestrus versus diestrus (a time of homeostatic negative feedback; Wang et al., 2016). Combined, these effects are thought to increase kisspeptin secretion onto the $\mathrm{GnRH}$ neuron, as increases in firing frequency are typically associated with increased neuropeptide release (Dutton and Dyball, 1979; Cropper et al., 2018). Estradiol positive feedback is likely conveyed to $\mathrm{GnRH}$ neurons by increased kisspeptin signaling, causing a surge of $\mathrm{GnRH}$ release which stimulates a luteinizing hormone (LH) surge from the pituitary. The LH surge stimulates ovulation (Greep et al., 1942).

Received August 3, 2021; accepted August 10, 2021; First published August 12, 2021.

The authors declare no competing financial interests.

Author contributions: J.R.S. and S.M.M. designed research; J.R.S. performed research; R.A.D. contributed unpublished reagents/analytic tools; J.R.S. analyzed data; J.R.S. and S.M.M. wrote the paper.

This work was supported by the National Institute of Health/Eunice Kennedy Shriver National Institute of Child Health and Human Development Grant R01HD41469 (to S.M.M.). J.R.S. was supported by the National Institute of Health/Eunice Kennedy Shriver National Institute of Child Health and Human Development Grant F31HD097830.

Acknowledgements: We thank Elizabeth Wagenmaker and Laura Burger for expert technical assistance and editorial comments. We also thank James $\mathrm{L}$. Kenyon, University of Nevada, Reno, for the Excel spreadsheet used to calculate junction potentials and Srinivas Gorur-Shandilya for help with xolotl software.

Correspondence should be addressed to Suzanne M. Moenter at smoenter@ umich.edu.

https://doi.org/10.1523/ENEURO.0324-21.2021

Copyright $@ 2021$ Starrett et al.

This is an open-access article distributed under the terms of the Creative Commons Attribution 4.0 International license, which permits unrestricted use, distribution and reproduction in any medium provided that the original work is properly attributed.
If the above theory is correct, the firing activity of AVPV kisspeptin neurons is a critical piece of this surge induction process, serving as a gating mechanism controlling kisspeptin release and thus the physiologic cascade culminating in ovulation. Several studies have focused on the electrical properties of these cells and how they change across the reproductive cycle, measured via recordings performed in acutely prepared mouse brain slices during periods of estradiol negative (typically diestrus) versus positive (proestrus) feedback. AVPV kisspeptin neurons recorded during proestrus maintain higher firing rates than during diestrus even when fast synaptic transmission was blocked, suggesting a shift in intrinsic properties across the diestrusproestrus transition enables increased firing during proestrus (Wang et al., 2016). Voltage-gated conductances may provide a basis for these shifts in activity since they help control membrane potential and shape firing dynamics in electrically-excitable cells. T-type calcium, persistent sodium, and hyperpolarization-activated currents were all found to be larger in AVPV kisspeptin neurons during proestrus (Piet et al., 2013; Zhang et al., 2015; Wang et al., 2016). Increases in these depolarizing currents, which can be active at subthreshold membrane potentials, could promote greater firing activity. Potassium currents, which strongly influence firing onset of many neurons and are vital for proper repolarization of the membrane (Hille, 2001), remained uncharacterized in AVPV kisspeptin neurons. $\mathrm{K}^{+}$currents change across the estrous cycle and in response to estradiol in $\mathrm{GnRH}$ neurons and kisspeptin neurons in the arcuate nucleus (DeFazio et al., 2002, 2019; Pielecka-Fortuna et al., 2011).

We hypothesized voltage-gated potassium currents in AVPV kisspeptin neurons are regulated by estrous cycle stage. Classic voltage-clamp approaches revealed three conductances contribute to the total voltage-gated potassium current in these cells, and each component was characterized during the afternoon of diestrus (negative feedback) and proestrus (positive feedback). It can be difficult to predict how multiple voltage-gated conductances interact to control the membrane voltage. Computational modeling studies were thus conducted to better understand how estrous cycle modulation of these and other currents influence action potential firing output.

\section{Materials and Methods}

\section{Animals}

The University of Michigan Institutional Animal Care and Use Committee approved all procedures. Adult female Kiss1-hrGFP mice (age 55-154 d) (Cravo et al., 2011) which express humanized Renilla GFP under control of the kisspeptin promoter, were used for these studies. Mice were provided with Harlan 2916 chow and water ad libitum and were held on a 14/10 h light/dark cycle with lights on at 3:00 A.M. Eastern Standard Time. Estrous cycle stage was monitored by vaginal cytology for at least oneweek before experiments. Uterine mass was 
measured after brain slice preparation to confirm cycle stage. Uterine mass $>100 \mathrm{mg}$ indicated in vivo exposure to a high concentration of estradiol, typical of proestrus, whereas mass $<60 \mathrm{mg}$ indicated exposure to low estradiol, typical of diestrus (Shim et al., 2000).

\section{Experimental design}

Brain slices were prepared from cycling adult female mice during cycle stages corresponding to estradiol negative feedback (afternoon of diestrus) or positive feedback (afternoon of proestrus). Whole-cell voltageclamp recordings of hrGFP-identified AVPV kisspeptin neurons were used to characterize macroscopic voltage-gated potassium currents; three currents (fast transient, slow transient, residual) were identified and separated using pharmacological and/or voltagebased subtraction methods for characterization. Current-clamp recordings were used to monitor action potential firing. Computational modeling was used to predict how each type of potassium current regulates AVPV neuron excitability, and how changes in multiple voltage-gated currents across the estrous cycle may impact excitability.

\section{Brain slice preparation}

Chemicals were purchased from Sigma-Aldrich unless noted. All solutions were bubbled with $95 \% \mathrm{O}_{2} / 5 \% \mathrm{CO}_{2}$ for at least $15 \mathrm{~min}$ before exposure to tissue. All mice were euthanized at 3-4 P.M. Eastern Standard Time, and the brain was rapidly removed and placed in ice-cold sucrose saline solution containing the following: $250 \mathrm{~mm}$ sucrose, $3.5 \mathrm{~mm} \mathrm{KCl}, 25 \mathrm{~mm} \mathrm{NaHCO}_{3}, 10 \mathrm{~mm}$ D-glucose, $1.25 \mathrm{~mm} \mathrm{Na}_{2} \mathrm{HPO}_{4}, 1.2 \mathrm{~mm} \mathrm{MgSO}_{4}$, and $3.8 \mathrm{~mm} \mathrm{MgCl}_{2}$, at $\mathrm{pH} 7.6$ and $345 \mathrm{mOsm}$. Coronal $(300 \mu \mathrm{m})$ slices were cut with a VT1200S Microtome (Leica Biosystems). Slices were incubated in a 1:1 mixture of sucrose saline and artificial CSF (ACSF) containing the following $135 \mathrm{~mm} \mathrm{NaCl}$, $3.5 \mathrm{~mm} \mathrm{KCl}, 26 \mathrm{~mm} \mathrm{NaHCO} 3,10 \mathrm{~mm}$ D-glucose, $1.25 \mathrm{~mm}$ $\mathrm{Na}_{2} \mathrm{HPO}_{4}, 1.2 \mathrm{~mm} \mathrm{MgSO}$, and $2.5 \mathrm{~mm} \mathrm{CaCl}_{2}$ at $\mathrm{pH} 7.4$ and $305 \mathrm{mOsm}$ for $30 \mathrm{~min}$ at room temperature $\left(\sim 21-23^{\circ}\right.$ C) and then were transferred to $100 \%$ ACSF for an additional 30-180 min at room temperature before recording. For recording, slices were placed into a chamber and perfused $(3 \mathrm{ml} / \mathrm{min})$ with carboxygenated ACSF kept at $31^{\circ} \mathrm{C}$ with an inline heating unit (Warner Instruments). GFP-positive AVPV kisspeptin neurons were identified by brief illumination at $488 \mathrm{~nm}$ on an Olympus BX51WI microscope. Recordings were performed $1-4 \mathrm{~h}$ after brain slice preparation. No more than four cells were recorded per mouse; data values from cells from the same animal were not clustered in a manner that would typically contribute to reduced variability.

\section{Voltage-clamp recordings}

Recording micropipettes were pulled from borosilicate capillary glass using a Flaming/Brown P-97 puller (Sutter Instruments) to obtain pipettes with a resistance of 1.53.5 $\mathrm{M} \Omega$ when filled with pipette solution, which consisted of $135 \mathrm{~mm} \mathrm{~K}$-gluconate, $10 \mathrm{~mm} \mathrm{KCl,} 10 \mathrm{~mm}$ HEPES, 5 mm EGTA, $0.1 \mathrm{~mm} \mathrm{CaCl}_{2}, 4 \mathrm{~mm}$ MgATP, and $0.4 \mathrm{~mm}$ NaGTP, 305 mOsm and pH 7.2 with $\mathrm{NaOH}$. Pipettes were wrapped in Parafilm to reduce capacitive transients. All potentials reported were corrected on-line for a liquid junction potential of $-15.7 \mathrm{mV}$ (Barry, 1994). Recordings were performed with one channel of an EPC-10 dual patch-clamp amplifier and PatchMaster software (HEKA Elektronik). After achieving the on-cell configuration with seal resistance $>2.0 \mathrm{G} \Omega$, fast capacitive transients were minimized and the whole-cell configuration was achieved by rupturing the cell membrane with brief suction. The membrane potential was held at $-70 \mathrm{mV}$ between voltage-clamp protocols. Passive membrane properties and voltage-clamp quality were calculated from the averaged current response (after on-cell capacitive current subtraction) to sixteen $-5 \mathrm{mV}, 20-\mathrm{ms}$ test pulses from a holding potential of $-70 \mathrm{mV}$ performed immediately before and after each protocol. To ensure adequate recording quality, the following criteria were required for inclusion for analysis: uncompensated series resistance (Rs) $<20 \mathrm{M} \Omega$, input resistance (Rinput) $>500 \mathrm{M} \Omega$, capacitance $(\mathrm{Cm})$ between 8 and $30 \mathrm{pF}$, holding current (Ihold) between -60 and $10 \mathrm{pA}$ (Table 1). Rs was compensated $50-85 \%$ for all protocols and recordings were excluded from analysis if $>20 \%$ change in Rs occurred during the experiment.

To isolate voltage-gated potassium currents, TTX $(2.5 \mu \mathrm{M}$, Tocris Bioscience), $\mathrm{CdCl}_{2}(100 \mu \mathrm{M})$, and $\mathrm{NiCl}_{2}(300 \mu \mathrm{M})$ were included in the ACSF to block $\mathrm{Na}^{+}$and $\mathrm{Ca}^{2+}$ currents. Picrotoxin $(100 \mu \mathrm{M})$ was used to block $\mathrm{GABA}_{A}$-receptor-mediated currents and D-(-)-2-amino-5-phosphonopentanoic acid (APV; $20 \mu \mathrm{Mm}$, Tocris Bioscience), and 6-cyano-7-nitroquinoxaline-2,3-dione (CNQX; $10 \mu \mathrm{m}$ ) were used to block ionotropic glutamate receptor-mediated currents.

\section{Total $\mathrm{K}^{+}$current}

In initial recordings of the total voltage-gated potassium current, two temporally-distinct peaks were visible in voltage steps from -100 to -10 or $0 \mathrm{mV}$. Further, a persistent negative slope in the outward current suggested a component with slow inactivation was present at potentials depolarized to $-10 \mathrm{mV}$. Lengthening the voltage-clamp protocols allowed for more complete removal or induction of inactivation before the test pulse. To measure the voltage dependence of activation of the total voltage-gated $\mathrm{K}^{+}$current, the membrane potential was held at $-100 \mathrm{mV}$ for $5 \mathrm{~s}$ to remove inactivation then stepped to test pulses of -70 to $+40 \mathrm{mV}$ (10-mV increments) for $1 \mathrm{~s}$. To measure the voltage dependence of inactivation, the membrane was held at potentials ranging from -100 to $-10 \mathrm{mV}(10-$ $\mathrm{mV}$ increments) for $10 \mathrm{~s}$ and then stepped to a test pulse of $0 \mathrm{mV}$ for $1 \mathrm{~s}$. The long duration of these protocols makes P/N subtraction (Armstrong and Bezanilla, 1977) unfeasible. Instead, slow $\mathrm{Cm}$ and leak current subtraction were performed offline by subtracting the appropriately scaled average current response to one hundred $-5 \mathrm{mV}$ test pulses with $\mathrm{Cm}$ and Rs compensation activated (Kimm et al., 2015). Averages were scaled for each voltage step used in the protocol. 


\section{Slow-transient $\mathrm{K}^{+}$current}

To characterize the slow transient $\mathrm{K}^{+}$current, the same activation/inactivation protocols as above were repeated with $5 \mathrm{~mm}$ 4-aminopyridine (4-AP) included in the ACSF to reduce primarily the fast-transient current. To measure the time course of inactivation of the slow-transient $\mathrm{K}^{+}$ current, the membrane was held at $-100 \mathrm{mV}$ for $5 \mathrm{~s}$ to remove inactivation, then at $-10 \mathrm{mV}$ for durations varying from 0 to $8 \mathrm{~s}$, followed by a test pulse at $0 \mathrm{mV}$ for $1 \mathrm{~s}$. To measure the time dependence of recovery from inactivation, the membrane was held at $-10 \mathrm{mV}$ for 10 s to inactivate the current, then at $-100 \mathrm{mV}$ for durations varying from 0 to $8 \mathrm{~s}$, followed by a test pulse at $0 \mathrm{mV}$ for $1 \mathrm{~s}$. Offline leak subtraction was used as for recordings of the total $\mathrm{K}^{+}$current (Kimm et al., 2015).

\section{Fast-transient $\mathrm{K}^{+}$current}

The fast-transient $\mathrm{K}^{+}$current was isolated and quantified using a voltage-based subtraction method after reducing primarily the slow-inactivating and residual components with ACSF in which $20 \mathrm{~mm}$ tetraethylammonium chloride (TEA) replaced $20 \mathrm{~mm} \mathrm{NaCl}$. To measure the voltage dependence of activation, two protocols (A and $B$ ) were run in series. For protocol $A$, the membrane potential was held at $-100 \mathrm{mV}$ for $200 \mathrm{~ms}$, then current was measured during 150 -ms test pulses from -70 to $+40 \mathrm{mV}$ (10$\mathrm{mV}$ increments). Protocol B was identical to protocol $\mathrm{A}$, except that the membrane potential was held at $-30 \mathrm{mV}$ rather than $-100 \mathrm{mV}$ during the first $200 \mathrm{~ms}$ of the proto$\mathrm{col}$. This fully inactivates the fast-transient current, isolating any remaining residual component during the test pulse. The current response during the test pulse of protocol B was subtracted from that of protocol A to yield the fast-transient current. To measure the voltage dependence of inactivation, the membrane was held at -100 to $-20 \mathrm{mV}$ (10-mV increments) for $200 \mathrm{~ms}$, before stepping to a test pulse at $-10 \mathrm{mV}(150 \mathrm{~ms})$. Current occurring after a step from $-30-\mathrm{mV}$ holding potential was defined as residual current and was subtracted from earlier sweeps to yield isolated fast transient current. To measure the rate of inactivation of the fast-transient $\mathrm{K}^{+}$current, inactivation was fully removed by holding the membrane at $-100 \mathrm{mV}$ for $300 \mathrm{~ms}$. The membrane was then stepped to $-30 \mathrm{mV}$ for $0-250 \mathrm{~ms}$ followed by a test pulse of $0 \mathrm{mV}$ for $100 \mathrm{~ms}$. The component of the current that did not inactivate (residual current) was subtracted from the prior series to isolate the fast-transient current. To measure the rate of the recovery from inactivation, the fast-transient current was fully inactivated by holding the membrane at $0 \mathrm{mV}$ for $300 \mathrm{~ms}$, then recovery prepulses at $-100 \mathrm{mV}$ were applied for $0-250 \mathrm{~ms}$ before measuring current at $0 \mathrm{mV}(100 \mathrm{~ms})$. The current after the 0-ms recovery prepulse was subtracted from each test pulse to isolate the fast-transient $\mathrm{K}^{+}$current. Slow $\mathrm{Cm}$ and leak currents were corrected using $\mathrm{P} /-5$ online leak subtraction with Vhold $=-70 \mathrm{mV}$ (Armstrong and Bezanilla, 1977).

It was not possible to quantify all parameters from every cell because not all cells remained within our quality control standards long enough for inclusion in the analysis of the time dependence of activation and inactivation. The number of cells and animals per measurement are shown in Tables 2, 3.

Total, fast-transient, slow-transient and residual $\mathrm{K}^{+}$current densities were calculated by dividing by $\mathrm{Cm}$. Peak values were divided by the driving force according to the Goldman-Hodgkin-Katz (GHK) current equation using the calculated reversal potential $(-94 \mathrm{mV}$; Clay, 2000, 2009). Conductance values were then normalized to the maximum conductance $\left(g_{\max }\right)$ to generate steady state activation/inactivation curves, which were fit with a Boltzmann function to calculate voltage of half $\left(\mathrm{V}_{50}\right)$ activation or inactivation, and steepness (k). Inactivation and recovery from inactivation curves were fit to single exponentials to measure time constants $(\tau)$.

\section{Current-clamp recordings}

Depolarizing (2-28 pA, 2-pA increments) and hyperpolarizing ( -25 to $-5 \mathrm{pA}, 5-\mathrm{pA}$ increments) current pulses (500 ms) were applied in whole-cell configuration. The maximum amplitude of hyperpolarizing stimuli was limited to avoid hyperpolarizing the membrane beyond $-100 \mathrm{mV}$, as further hyperpolarization was detrimental to recording stability. The targeted initial membrane potential was within $2 \mathrm{mV}$ of $-70 \mathrm{mV}$, which is close to the baseline membrane potential of these cells (DeFazio et al., 2014). Spikes were counted as action potentials only if their peak value was depolarized relative to $-10 \mathrm{mV}$; spike number was plotted as a function of current injection.

\section{Modeling}

For physiologic data used, mean \pm SEM normalized activation, inactivation, recovery, and rate of inactivation curves were calculated for the total, fast-transient (fast), slow-transient (slow), and residual (resid) $\mathrm{K}^{+}$current densities in each group. Leak-subtracted current traces from activation protocols were averaged for each current at each voltage step to obtain mean \pm SEM current traces used for fitting. T-type calcium and persistent sodium conductance data were collected from published measurements, which indicated larger amplitudes during proestrus (Zhang et al., 2015; Wang et al., 2016). The hyperpolarization-activated conductance was estimated based on the amplitude and time course of the sag potential, which has larger amplitude during proestrus (Piet et al., 2013; Wang et al., 2016). Neurons were modeled as a single compartment with whole-cell $\mathrm{Cm}$ of $17.62 \mathrm{pF}$ based on the mean of experimentally-observed values (Table 1).

\section{Equations}

$\mathrm{Na}^{+}, \mathrm{Ca}^{2+}$, and hyperpolarization-activated currents were modeled based on Ohmic driving forces (Eq. 1-2). $\mathrm{K}^{+}$currents were modeled based on nonlinear driving forces described by the GHK current equation (Eq. 3; Clay, 2000, 2009).

$$
I=C_{m} \frac{d \mathrm{~V}}{d t}+I_{\text {NaT }}+I_{\text {NaP }}+I_{\text {CaT }}+I_{h}+I_{\text {resid }}+I_{\text {fast }}+I_{\text {slow }}+I_{\text {Leak }}
$$

$$
I_{a}=\bar{g}_{a} m^{r} h\left(V-E_{a}\right), a=N a_{p}, C a_{T}, h, \text { Leak }
$$


Table 1: Passive properties and statistical comparisons

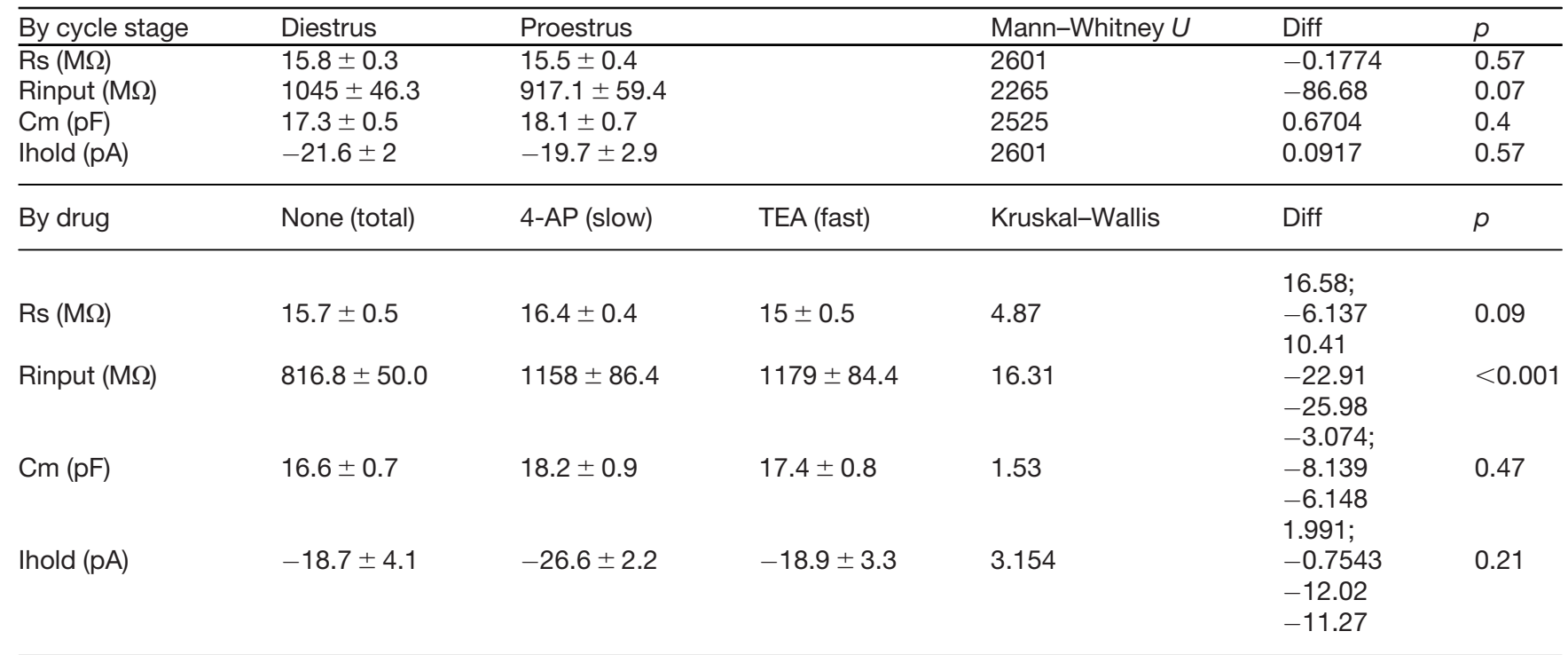

$$
I_{b}=\bar{g}_{b} m h \frac{q V}{k T} \frac{e^{\frac{q\left(V-E_{b}\right)}{k T}}-1}{e^{\frac{q V}{k T}}-1}, b=\text { resid, fast, slow. }
$$

I is current (nA) across the neuronal membrane, $C_{m}$ is the cell $\mathrm{Cm}(\mathrm{pF}), V_{m}$ is the membrane potential $(\mathrm{mV}), t$ is time (ms), $\bar{g}_{a}$ is the specific conductance (nS), $E_{a}$ is the reversal potential $(\mathrm{mV})$ of a given ion, $q$ is the elementary charge, $k$ is the Boltzmann constant, $T$ is the absolute temperature, and $m$ and $h$ represent activation and inactivation variables, respectively. Exponents $r$ represents the number of activation particles. These variables are governed by the following differential equations (Eqs. 4, 5)

$$
\begin{gathered}
\frac{d m}{d t}=\frac{m_{\infty}(\mathrm{V})-m}{\tau_{m}(\mathrm{~V})} \\
\frac{d h}{d t}=\frac{h_{\infty}(\mathrm{V})-h}{\tau_{h}(\mathrm{~V})},
\end{gathered}
$$

where $m_{\infty}(V)$ and $h_{\infty}(V)$ are the steady-state activation/inactivation functions for each variable and $\tau_{m}$ and $\tau_{h}$ are functions determining the voltage-dependent time constants (in ms) of activation/deactivation and inactivation/ recovery, respectively. These functions take the form (Eq 6-9). A-G are free parameters adjusted during fitting.

$$
\begin{aligned}
& m_{\infty}, h_{\infty}=\frac{1}{1+e^{\frac{\left(v_{50}, h-v\right)}{K_{m, h}}}} \\
& \tau_{m_{a}}, \tau_{h_{a}}=A+\frac{B}{1+e^{\left(\frac{V-C}{D}\right)}} * \frac{E}{1+e^{\left(\frac{V}{G}-F\right.}}, a=\text { slow, resid } \\
& \tau_{m_{a}}, \tau_{h_{a}}=A+\frac{B}{1+e^{\left(\frac{V-C}{D}\right)}}, a=\text { fast, } H, C a T \\
& \tau_{\text {NaP }}=\frac{E}{e^{\frac{A+V}{B}}+e^{\frac{C+V}{D}}}+F .
\end{aligned}
$$

The transient sodium current $\left(\mathrm{Na}_{T}\right)$ was modeled used a Markov chain with three states, open $(O)$, closed $(C)$, or inactivated $(I)$. Transitions between states were either voltage sensitive or constants. The model used was modified from Adams et al., 2018. (Eq. 10-14).

$$
\begin{gathered}
I_{\mathrm{NaT}}=\bar{g}_{\mathrm{NaT}} \mathrm{O}^{3}\left(V-E_{\mathrm{Na}}\right) \\
\alpha(V), \beta(V), r_{1}(V), r_{3}(V)=\frac{r}{1+e^{\frac{(V+s)}{k}}} \\
\frac{d C}{d t}=\beta(\mathrm{V}) \mathrm{O}+r_{3}(V) I-\alpha(\mathrm{V}) \mathrm{C} \\
\frac{d O}{d t}=\alpha(\mathrm{V}) \mathrm{C}-\left(\beta(\mathrm{V})+r_{1}(V)\right) \mathrm{O} \\
I=1-\mathrm{C}-\mathrm{O} .
\end{gathered}
$$

\section{Parameter optimization}

Simulated voltage-clamp experiments were performed using xolotl (Gorur-Shandilya et al., 2018) in MATLAB (MathWorks) running on a Windows 10 PC. Voltage-step protocols matched those used experimentally for each conductance. Current traces generated by models were analyzed in the same manner as the slice recording data. For each voltage step, peak currents were converted to conductance and normalized to generate activation/inactivation curves. For $\mathrm{K}^{+}$models, permeability as calculated by the GHK current equation was used (Clay, 2000, 2009). $m_{\infty}$ and $h_{\infty}$ function parameters were adjusted manually until the normalized activation/inactivation curves were well fit to the experimental data. $\tau_{m}, \tau_{h}$, and $\bar{g}$ parameters were also adjusted so that the rise and decay (where applicable) phases of the current trace and peak amplitudes were well-fit to the data. This process was iterative and was greatly facilitated by xolotl's "puppeteer" function, which allowed for rapid-recalculation and visualization of simulation results following parameter adjustment. Separate models were generated for each experimental 
group to reproduce estrous cycle effects on each of the voltage-gated currents.

The total $\mathrm{K}^{+}$current was fit by simulating voltage-clamp of a cell containing the three $\mathrm{K}^{+}$conductance subcomponents (fast, slow, resid) as they were fit to their respective drug-separated recordings. To better fit the total $\mathrm{K}^{+}$recording, $\bar{g}$ parameters were optimized using particle swarm optimization (Global Optimization Toolbox, MathWorks), which sought to minimize the sum of squares error between the current trace generated by the model and the mean data for the respective conductance.

\section{Simulation of excitability}

To study action potential firing, diestrous and proestrous neuron models were built with an identical sodium channel model. This model was made the same between groups because, although there are no experimental data characterizing this conductance in AVPV kisspeptin neurons, action potential threshold (defined as when rate of rise exceeds $2 \mathrm{~V} / \mathrm{s}$ ) and amplitude were the same between cycle stages (Wang et al., 2016), and these characteristics are highly influenced by transient sodium current properties (Kress et al., 2010).

To examine how conductances alter firing, a suite of conductance models corresponding to the respective experimental group were added to single-compartment neuron models, and the voltage of the model was allowed to vary, i.e., "current clamp." Using the same protocols from in vitro recordings, firing was stimulated by applying increasing current steps $(-30-0 \mathrm{pA}$ at $10-\mathrm{pA}$ intervals, 2$28 \mathrm{pA}$ at 2-pA intervals) to the model cell at a baseline membrane potential of $-70 \mathrm{mV}$. The number of spikes fired during the stimulation is plotted against the stimulation amplitude to generate a firing-current (F-I) curve. To achieve this baseline potential, Ihold and leak conductance were adjusted so that the membrane potential before the start of the current pulse was within $50 \mu \mathrm{V}$ of $-70 \mathrm{mV}$ and Rinput was $1 \mathrm{G} \Omega$ (passive properties in Table 1). For diestrous and proestrous models, the simulated rheobase action potential waveform was compared with the peak-aligned mean rheobase action potential of the corresponding experimental group. This fit was improved by manually adjusting sodium conductance model parameters; adjustments were kept the same for the diestrous and proestrous models. To test predictions regarding estrous cycle effects or the role and/or interaction of various conductances, individual or multiple conductances fit to diestrous data were substituted into the proestrous model (and vice versa) for a particular simulation.

\section{Code accessibility}

The code described in the paper is freely available online at https://github.com/JRS92/Starrett_eNeuro_2021. The $\mathrm{C}++$ files containing xolotl conductance code is available as Extended Data 1.

\section{Statistics}

Data were analyzed using Prism 9 (GraphPad). ShapiroWilk was used to test distribution of data. Parameters (mean \pm SEM) were compared between cycle stages with unpaired statistical tests appropriate for experimental design and data distribution as indicated in the results section. The number of cells per group is indicated by $n$. For two-way ANOVAs and Mann-Whitney, difference of the means (Diff) was defined for cycle stage (diestrus-proestrus). For Kruskal-Wallis tests (Table 1), mean rank differences are reported as (total - slow), (total - fast), (slow fast). Significance was set at $p<0.05$.

\section{Results}

\section{Passive properties}

Rs, Rinput, $\mathrm{Cm}$, and Ihold measurements were made before and after each protocol and values were averaged for each cell. There were no statistical differences between cells recorded during diestrus versus proestrus for any of the measured properties (Table 1). Comparing across drug treatments that are discussed below, Rinput was higher during 4-AP or TEA treatment (Table 1). Dunn's multiple comparison post hoc tests of Rinput revealed increases consistent with antagonism of channels active at baseline membrane potentials by the respective drugs (Dunn's, control vs 4-AP $p=0.002$, control vs TEA $p=0.001,4$-AP vs TEA $p>0.99$ ).

\section{Total voltage-dependent $\mathrm{K}^{+}$current in AVPV kisspeptin neurons has multiple components}

In nocturnal rodents, positive feedback needed to generate the LH surge occurs during the afternoon of proestrus (Brown-Grant et al., 1970; Sarkar et al., 1976). During this time, both overall firing rate and burst firing of AVPV kisspeptin neurons increase relative to diestrus (Wang et al., 2016). Given the importance of $\mathrm{K}^{+}$currents in determining the excitability and firing patterns of neurons (Coetzee et al., 1999; Hille, 2001), we hypothesized voltage-gated potassium currents are targets of estradiol feedback in AVPV kisspeptin neurons; we tested this using whole-cell voltage-clamp. Figure $1 A$ shows a representative recording of total voltage-dependent $\mathrm{K}^{+}$current activation. Examining this family of traces from the most hyperpolarized to the most depolarized command potentials revealed induction of one component with faster inactivation at more hyperpolarized potentials that merged with a component that activated at more depolarized potentials and only slowly inactivated. The slow kinetics of the macroscopic current resembled a $\mathrm{K}^{+}$current previously observed in dorsal root ganglion neurons (Gold et al., 1996), and led us to extend the duration of the prepulses beyond what is used in a typical inactivation protocol to $10 \mathrm{~s}$ (Fig. 1B). As described above, a fast component can be seen to activate and inactivate within $\sim 50 \mathrm{~ms}$ at more hyperpolarized potentials during the prepulse (expanded in Fig. 1C, left); this component is prominent as a spike during the test pulse following hyperpolarized prepulses (expanded in Fig. $1 C$, right). A second component required greater depolarization to begin activating and inactivated slowly only at more depolarized potentials. The peak total current density (derived from the voltage-clamp protocol in Fig. $1 A$ ) was not 
A

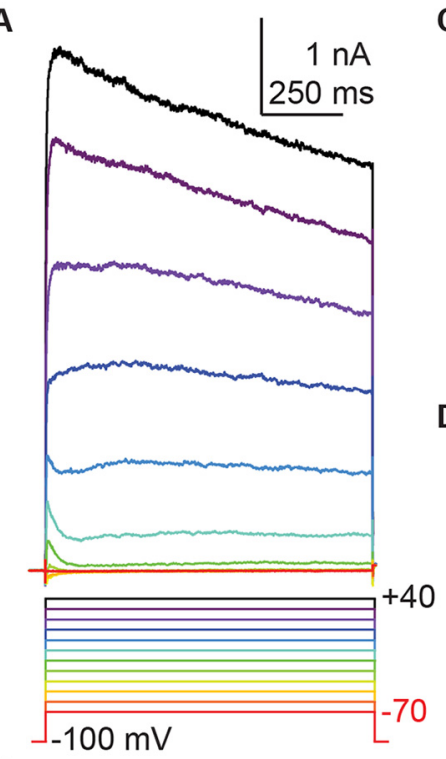

B
C

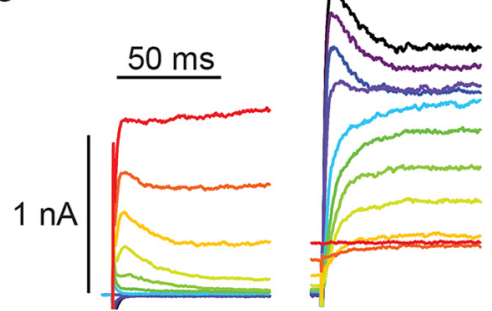

D

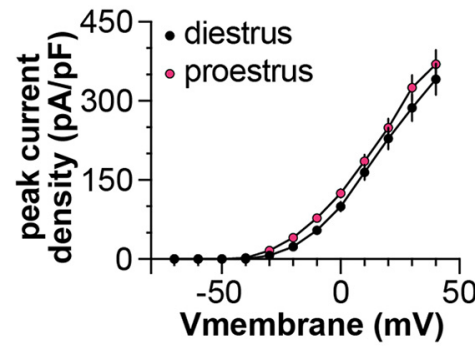

$-100 \mathrm{mV}$

Figure 1. Total voltage-dependent $\mathrm{K}^{+}$current in AVPV kisspeptin neurons has three distinct components. $\boldsymbol{A}$, Representative total $\mathrm{K}^{+}$current in response to the voltage-clamp protocol shown. $\boldsymbol{B}$, Representative recording of total $\mathrm{K}^{+}$current from a different cell in response to the voltage protocol shown; both a slowly-inactivating and residual (sustained) component are evident during the extended prepulse. $\boldsymbol{C}$, Expansions of the areas within the dashed boxes in $\boldsymbol{B}$, showing the change in inactivation rates as more depolarizing prepulses are applied (left), and how this affects both activation and inactivation during the test pulse (right). $\boldsymbol{D}$, Mean \pm SEM peak current density in cells from mice in diestrus (black symbols) and proestrus (magenta symbols). Error bars are smaller than symbols for some values.

different between diestrus and proestrus at any of the potentials tested (Fig. 1D, two-way repeated-measures ANOVA for effect of cycle stage; Table 2). These observations, however, do not preclude latent changes attributable to individual components being differentially regulated.

\section{Pharmacological treatments to isolate current components}

To attempt to isolate the components of the total potassium current, recordings were made before and during application of the potassium channel blockers TEA (20 $\mathrm{mM}$ ) or 4-AP (5 mM). TEA reduced the amplitude of both the fast and slow components, but the reduction in the slow component was proportionally greater, making the fast peak appear more prominent (Fig. 2A). Lower concentrations of TEA ( $500 \mu \mathrm{m}$ to $10 \mathrm{~mm})$ did not block most of the slow peak amplitude and were thus less effective in revealing the fast component. The fast-transient component was markedly reduced by $5 \mathrm{~mm}$ 4-AP (Fig. 2B, note right-shift of peak in red trace). Lower concentrations of 4-AP $(100 \mu \mathrm{m}$ to $1 \mathrm{~mm})$ did not block the fast initial peak at $-10 \mathrm{mV}$. These changes were attributable to drug action rather than rundown as the current remained stable in the absence of treatments over the $10 \mathrm{~min}$ required for these recordings (Fig. 2C).
Individual components of the total current may have distinct roles in determining firing output and may also be independently regulated by cycle stage. The differential effects of TEA and 4-AP were used to perform more detailed characterization of the sub-components of the total potassium current in AVPV neurons in slices from diestrous and proestrous mice. To increase recording yield, we switched from a within-cell design to a population (i.e., among-cell) design, with drug present from the time the slice was placed in the recording chamber. In these population studies, the longer exposure to TEA caused a larger reduction in peak current density. Specifically, the peak current density at $+40 \mathrm{mV}$ during TEA treatment was $76.6 \pm 5.1 \%$ of pretreatment values in within-cell experiments, but only $53.0 \pm 3.7 \%$ of untreated cells in population studies. This greater reduction was not observed with 4-AP [the peak current density during 4-AP treatment was $76.6 \pm 4.9 \%$ of the control period for within-cell studies $(n=3)$, and $76.1 \pm 9.9 \%$ of untreated controls in population studies $(n=4)]$.

\section{The slow-transient component is increased on diestrus}

The extended duration voltage-clamp protocols were used to characterize the slow-transient potassium current 
Table 2: Two-way ANOVA analyses of $\mathrm{K}^{+}$current properties

\begin{tabular}{|c|c|c|c|c|}
\hline \multirow[b]{2}{*}{ Total } & \multicolumn{2}{|c|}{$\begin{array}{l}n \text { cells, } \\
n \text { animals }\end{array}$} & \multirow[t]{2}{*}{ Estrous stage } & \multirow[t]{2}{*}{$\begin{array}{l}\text { Estrous stage } \times \text { Vm or } \\
\text { duration interaction }\end{array}$} \\
\hline & $\mathrm{di}$ & pro & & \\
\hline Density & 10,4 & 17,5 & Diff, $-15.42[\mathrm{Cl}-40.49,9.660] F_{(1,25)}=1.603 ; p=0.217$ & $F_{(11,275)}=0.6496 p=0.785$ \\
\hline \multicolumn{5}{|c|}{$\log$} \\
\hline Density & 12,5 & 13,5 & Diff, $24.07[\mathrm{Cl}-5.523,53.66] F_{(1,23)}=6.503 ; p=0.106$ & $F_{(8,184)}=10.03 p<0.001$ \\
\hline Activation & 12,5 & 13,5 & Diff, $-0.01901[\mathrm{Cl}-0.06921,0.03120] F_{(1,25)}=5.283 ; p=0.442$ & $F_{(11,275)}=3.336 p=0.169$ \\
\hline Inactivation & 9,4 & 12,5 & Diff, $-0.0009547[\mathrm{Cl}-0.06269,0.06078] F_{(1,20)}=0.1782 ; p=0.975$ & $F_{(12,240)}=0.1988 p>0.999$ \\
\hline Rate of inactivation & 10,7 & 9,4 & Diff, $-0.03472[\mathrm{Cl}-0.08026,0.01082] F_{(1,17)}=2.587 ; p=0.126$ & $F_{(14,238)}=1.336 p=0.187$ \\
\hline Rate of recovery & 9,5 & 13,5 & Diff, $-0.05901[\mathrm{Cl}-0.09461,-0.02342] F_{(1,20)}=10.52 ; p=0.002$ & $F_{(14,280)}=4.006 p<0.001$ \\
\hline \multicolumn{5}{|c|}{$x_{0}$} \\
\hline Density & 11,4 & 13,4 & Diff, $-6.607[\mathrm{Cl}-22.53,9.317] F_{(1,22)}=0.7404 ; p=0.399$ & $F_{(11,242)}=0.9366 p=0.506$ \\
\hline Activation & 11,4 & 13,4 & Diff, $0.01876[\mathrm{Cl}-0.03188,0.06940] F_{(1,23)}=0.6133 ; p=0.450$ & $F_{(8,184)}=1.475 p=0.981$ \\
\hline Inactivation & 11,4 & 12,4 & Diff, $-0.05682[\mathrm{Cl}-0.1119,-0.001691] F_{(1,21)}=4.594 ; p=0.044$ & $F_{(9,189)}=4.041 p<0.001$ \\
\hline Rate of inactivation & 10,4 & 12,4 & Diff, $-0.0085[\mathrm{Cl}-0.03704,0.02004] F_{(1,20)}=0.3859 ; p=0.541$ & $F_{(11,220)}=0.4253 p=0.944$ \\
\hline Rate of recovery & 10,4 & 12,4 & Diff, $-0.01081[\mathrm{Cl}-0.03695,0.01532] F_{(1,20)}=0.7448 ; p=0.398$ & $F_{(11,220)}=0.3670 p=0.967$ \\
\hline \multicolumn{5}{|l|}{ Residual } \\
\hline Density & 11,4 & 13,4 & Diff, $0.07334[\mathrm{Cl}-3.263,3.409] F_{(1,22)}=0.002079 ; p=0.964$ & $F_{(11,242)}=0.05676 p>0.999$ \\
\hline Activation & 11,4 & 13,4 & Diff, $0.01068[\mathrm{Cl}-0.03932,0.06068] F_{(1,22)}=0.1962 ; p=0.662$ & $F_{(11,242)}=0.2095 p=0.997$ \\
\hline
\end{tabular}

Bold font indicates $p<0.05$

in the presence of 4-AP; representative traces are shown in Figure 3. Peak current density was greater in cells from diestrous $(n=12)$ than proestrous $(n=13)$ mice at more depolarized potentials (Fig. $3 C$, two-way repeated-measures ANOVA for effect of cycle stage; Table 2). The slow current was activated at command voltages at and depolarized relative to $-20 \mathrm{mV}$. Normalized activation and inactivation curves were not different between groups (Fig. $3 D$, two-tailed Student's $t$ test with Welch's correction for $\mathrm{V}_{50}$ activation, inactivation; Table 3 ). Time course of inactivation was not different between diestrus and proestrus (Fig. 3F,H, two-way repeated-measures ANOVA for effect of cycle stage; Table 2). In contrast, recovery from inactivation was more rapid during proestrus (Fig. 3G, $H$, twoway repeated-measures ANOVA for effect of cycle stage; Table 2). In recovery from inactivation experiments, the recovery of two currents was evident. The fast transient was visible when the hyperpolarizing recovery prepulse was shorter than $200 \mathrm{~ms}$ (Fig. 3G, arrow). This may be attributable to the voltage dependence of 4-AP action, in which the channel becomes unblocked during depolarization (Choquet and Korn, 1992; Kehl, 2017). The slow current was visible $70-150 \mathrm{~ms}$ into the test pulse. To avoid contamination with the fast current, for this protocol only the peak of the slow transient current was taken as the maximum current $70-150 \mathrm{~ms}$ after the start of the test pulse.

\section{The inactivation curve of the fast-transient component is depolarized during proestrus}

Bath-applied $20 \mathrm{~mm}$ TEA preferentially reduced the amplitude of the slow-transient current, allowing better characterization of the fast-transient current. Because

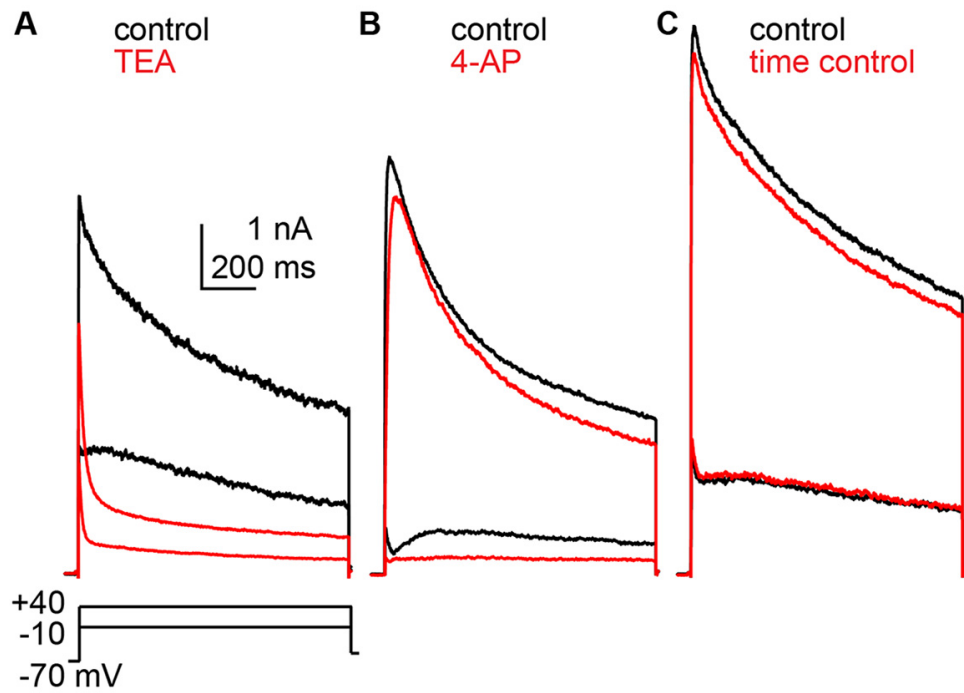

Figure 2. Potassium current recorded from three different cells before and during application of potassium channel blockers. $\boldsymbol{A}$, 20 mm TEA. $\boldsymbol{B}, 5 \mathrm{~mm}$ 4-AP. $\boldsymbol{C}$, Time control. 
A

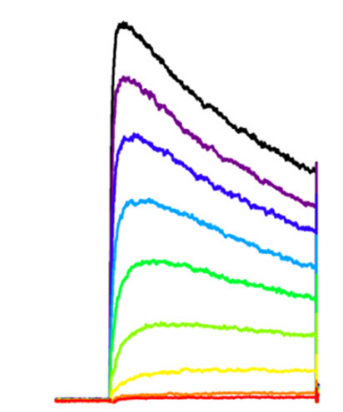

B

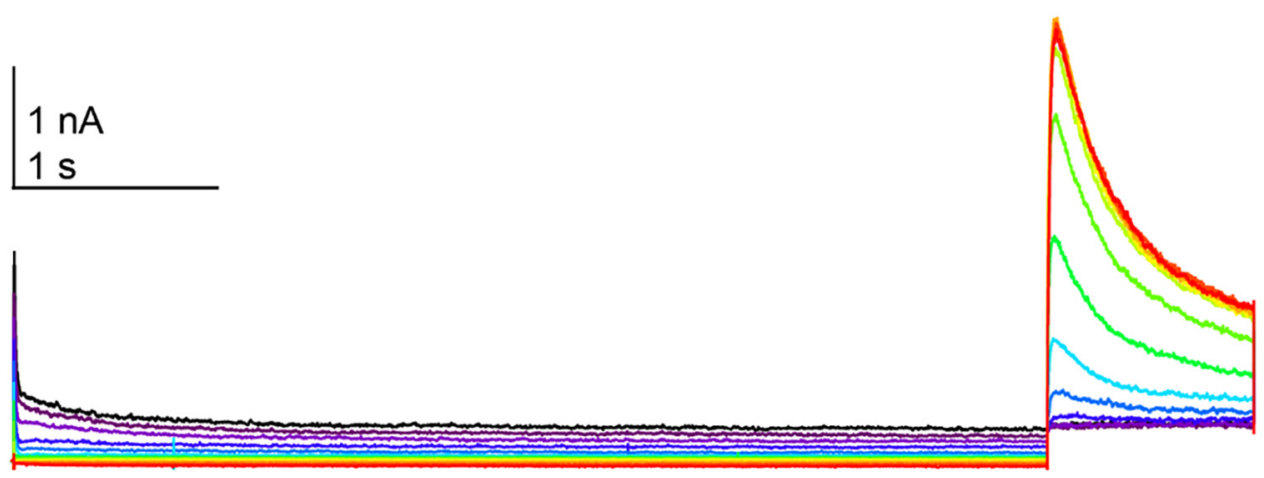

$+40$

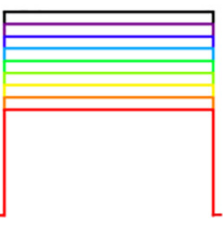

$-100$

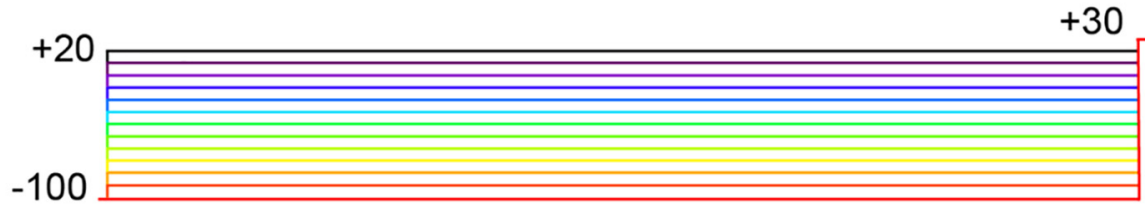

C

D
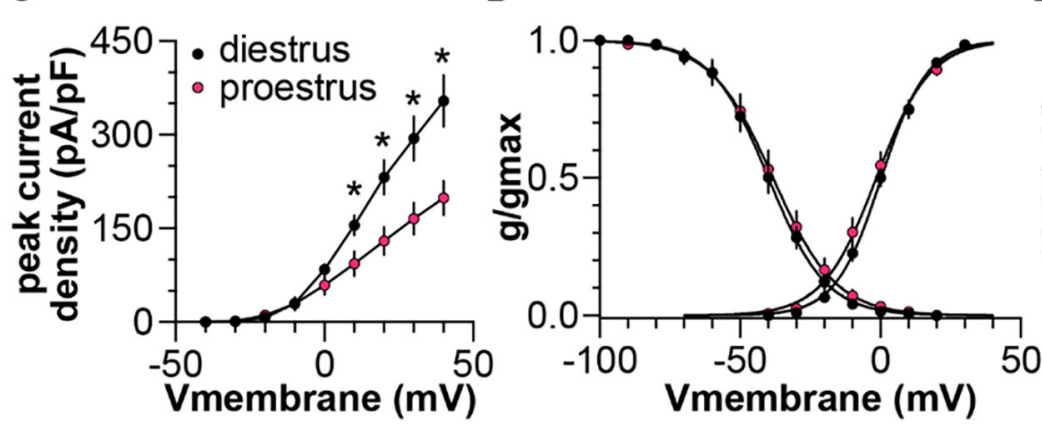

E

$\mathbf{F}$

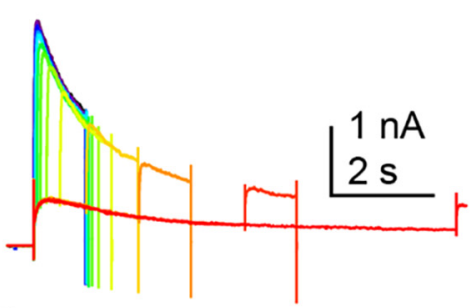

G

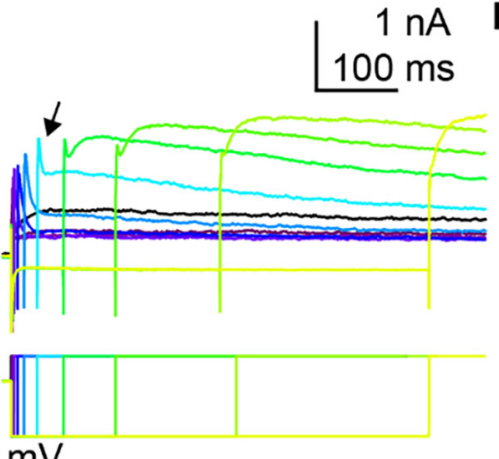

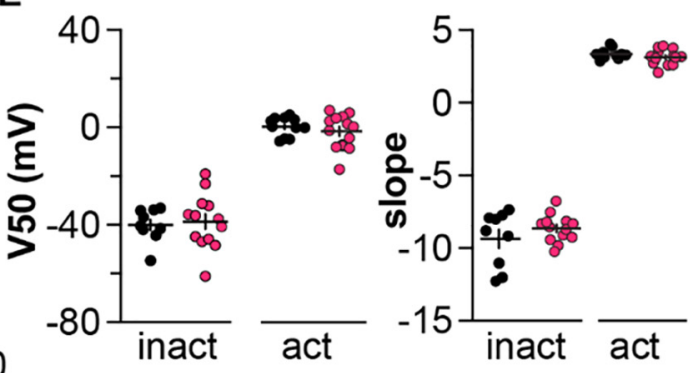

\section{$-100 \overline{\mathrm{mV}}$}

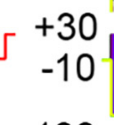

$-100 \mathrm{mV}$

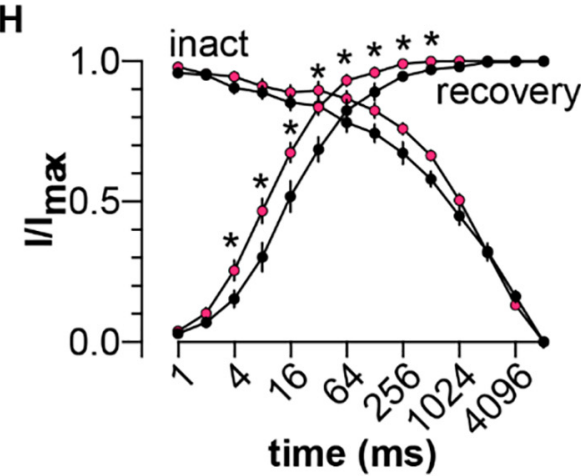

Figure 3. 4-AP-resistant slow-transient voltage-dependent $\mathrm{K}^{+}$current is larger on diestrus. $\boldsymbol{A}$, Representative traces (top) in response to the activation voltage-clamp protocol (bottom) in the presence of $5 \mathrm{~mm}$ 4-AP. $\boldsymbol{B}$, Representative traces (top) in response to the inactivation voltage-clamp protocol (bottom). Offline leak subtraction was applied to test pulses only, hence the $\mathrm{Cm}$ transient is visible at the start of the recording. $\boldsymbol{C}$, Mean \pm SEM peak current density from cells in mice in diestrus (black symbols) and proestrus (magenta symbols). $\boldsymbol{D}$, Mean \pm SEM normalized conductance. Solid lines are Boltzmann fits to the mean data. $\boldsymbol{E}$, Individual values and mean \pm SEM parameters obtained from Boltzmann fits to normalized conductance curves for each cell. $\boldsymbol{F}$, $\boldsymbol{G}$, Representative traces (top) in response to the voltage-clamp protocol (bottom) used to measure the time dependence of inactivation $(\boldsymbol{F})$ and recovery $(\boldsymbol{G})$. Arrow denotes peak of fast transient current. $\boldsymbol{H}$, Mean \pm SEM normalized peak current versus prepulse duration for time dependence of inactivation (inact) and recovery from inactivation. Error bars are smaller than symbols for some values; ${ }^{*} p<0.05$.

this fast-transient component activated and inactivated quickly, voltage-clamp protocols with more traditional durations were used (Fig. 4A). Under these recording conditions, a fast-transient current began to activate between -50 and $-40 \mathrm{mV}$ (Fig. $4 \mathrm{C}$ ); current reached a non-zero steady state by the end of the test pulse, suggesting a contribution by non-inactivating or slowly-inactivating channels. To isolate the fast-transient current from this non-inactivating residual component, a voltage-based subtraction method was used. Subtraction of the residual current following a depolarizing prepulse (Fig. 4A, middle) yielded a transient current that was almost fully 
Table 3: Two-sample analyses of $\mathbf{K}^{+}$current properties

\begin{tabular}{|c|c|c|c|c|}
\hline Property & $n$ cells, & $n$ animals & Difference (Diff), $\mathrm{Cl}, t$ or $U, \mathrm{df}, p$ & Notes \\
\hline & di & pro & & \\
\hline Slow $\mathrm{V}_{50}$ activation & 12,5 & 13,5 & Diff, $-1.888[\mathrm{Cl}-6.587,2.811] t=0.8428, \mathrm{df}=18.42, p=0.410$ & Welch's correction \\
\hline Slow activation slope & 12,5 & 13,5 & Diff, $-0.2234[\mathrm{Cl}-0.6005,0.1537] t=1.225, \mathrm{df}=23, p=0.233$ & \\
\hline Slow $\mathrm{V}_{0}$ inactivation & 9,4 & 12,5 & Diff, $1.42[\mathrm{Cl}-7.327,10.17] t=0.3386, \mathrm{df}=20, p=0.738$ & \\
\hline Slow inactivation slope & 9,4 & 12,5 & Diff, $0.7169[\mathrm{Cl}-0.8095,2.243] t=1.038, \mathrm{df}=10.67, p=0.322$ & Welch's correction \\
\hline Fast $\mathrm{V}_{50}$ & 11,4 & 13,4 & Diff, $2.201[\mathrm{Cl}-4.110,8.513] t=0.7233, \mathrm{df}=22, p=0.477$ & \\
\hline Fast activation slope & 11,4 & 13,4 & Diff, $0.451[\mathrm{Cl}-0.5518,1.454] t=0.9327, \mathrm{df}=22, p=0.361$ & \\
\hline Fast $\mathrm{V}_{50}$ inactivation & 11,4 & 12,4 & Diff, $6.23[\mathrm{Cl} 0.09700,12.36] t=2.180, \mathrm{df}=13.92, p=0.047$ & Welch's correction \\
\hline Fast inactivation slope & 11,4 & 12,4 & Diff, $-0.1266[\mathrm{Cl}-0.9059,0.6526] t=0.3379, \mathrm{df}=21, p=0.739$ & \\
\hline Residual $\mathrm{V}_{50}$ activation & 11,4 & 13,4 & Diff, $1.329[\mathrm{Cl}-4.612,7.269] t=0.4638, \mathrm{df}=22, p=0.647$ & \\
\hline Residual activation slope & 11,4 & 13,4 & Diff, $0.1930 U=61 ; p=0.569$ & Mann-Whitney \\
\hline
\end{tabular}

Bold font indicates $p<0.05$. Differences shown for means for normally-distributed data and medians for non-normally-distributed data.

inactivated by the end of the test-pulse (Fig. $4 A$, right). The $V_{50}$ activation of the residual current was more depolarized than that of the fast-transient current at both cycle stages (Fig. $4 B-D$, diestrus $n=11$, proestrus $n=13$, one-way ANOVA $F_{(3,44)}=10.8, p<0.001$; Tukey residual vs fast $p=0.001$ for proestrus, residual vs fast $p=0.002$ for diestrus). There was no effect of cycle stage on the peak current density of either the fast-transient or residual component (Fig. $4 B$, two-way repeated-measures ANOVA for effect of cycle stage; Table 2). In contrast, cycle stage affected voltage dependence of the fast-transient component. Specifically, inactivation of the fast transient occurred at more depolarized potentials on proestrus than diestrus (Fig. 4C,E, two-way repeated-measures ANOVA for effect of cycle stage on inactivation; Table 2; unpaired two-tailed Student's $t$ test with Welch's correction of $V_{50}$ inactivation; Table 3 ), Cycle stage did not, however, affect the voltage dependence of activation (Fig. 4C, two-way repeated-measures ANOVA for effect of cycle stage on activation curve; Table 2) or $\mathrm{V}_{50}$ activation (Fig. $4 D$, unpaired two-tailed Student's $t$ test; Table 3). Full inactivation and full recovery of the fast transient occurred in $<100 \mathrm{~ms}$ (Fig. 4F,G). There was no group difference in either of these properties (two-way repeated-measures ANOVAs for effect of cycle stage; Table 2).

\section{Modeling conductances}

Computational modeling was used to better understand the role of estrous cycle modulation of multiple conductance types in the control of AVPV kisspeptin neuron firing. Specifically, we examined whether estrous cycle-related shifts in $\mathrm{K}^{+}$current components and/or subthreshold depolarizing currents alter the firing dynamics of these cells. To model subcomponents in silico, Hodgkin-Huxley conductance models were fit to mean \pm SEM recordings of drug-separated and voltage-separated subcomponents of the $\mathrm{K}^{+}$current: slow, fast, and residual. This involved adding individual subcomponents to single-compartment neuron models and running such models through the same voltage-clamp protocols used experimentally, generating membrane current over time plots. Model output was compared with experimental data (Fig. 5), and $m_{\infty}(\mathrm{V})$, $\mathrm{h}_{\infty}(\mathrm{V}), \tau_{\mathrm{m}}(\mathrm{V})$, and $\tau_{\mathrm{h}}(\mathrm{V})$ function parameters were changed iteratively to improve the quality of fit. Steady-state activation and inactivation curves and I(density)-V plots were calculated from the model output and compared with experimental data for $\mathrm{K}^{+}$currents (Fig. $6 A, B, D$ ) and for CaT (Fig. 6C,F) and NaP (Fig. 6E) currents reported (Zhang et al., 2015; Wang et al., 2016).

To reconstruct the total $\mathrm{K}^{+}$current from the sum of the subcomponents, the set of $I_{\text {slow }}, I_{\text {fast }}$, and $I_{\text {resid }}$ currents for each group were included in single neuron models, and the models were run through the same voltage-clamp protocol used for recordings in Figure $1 A$. Initial simulations indicated the sum of fast, slow, and residual conductance models as fit to their respective isolated recordings was not enough to account for the full amplitude of the total $\mathrm{K}^{+}$current, suggesting subcomponents were blocked to some degree by the drug used to isolate them (i.e., 4-AP blocked a portion of the slow current, TEA blocked some of the fast and residual currents). To overcome this problem, particle-swarm optimization was used to minimize the error between the model-generated current trace and the mean \pm SEM trace by optimizing $\bar{g}$ parameters of each subcomponent, with equal weighting across the trace. This preserved the voltage-sensitivity and kinetics of the subcomponents as fit in the drugseparated and voltage-separated recordings (Fig. 5) while providing a better fit to the experimental data. Parameter values are shown in Tables 4, 5. This approach provided a good fit to peak current density (Fig. $7 A$ ) and the first $\sim 250 \mathrm{~ms}$ of the total $\mathrm{K}^{+}$current (Fig. $7 B$ ). The error between the model and data increased as the simulation progressed, however. This error could be reduced by decreasing the inactivation rate of $\mathrm{I}_{\text {slow }}$, but this modification had no effect on firing behavior as measured in response to 500-ms current pulses, suggesting this shift in kinetics does not substantially influence firing output at these timescales (data not shown).

\section{Simulations of firing}

$\mathrm{K}^{+}$conductance models from fits to the total $\mathrm{K}^{+}$current, $\mathrm{CaT}, \mathrm{NaP}$, and $\mathrm{HCN}$ conductances for the diestrous and proestrous groups were combined into single-compartment neuron models, thus creating neuron models with seven voltage-gated conductances and one leak conductance each. A transient sodium (NaT) conductance is needed to enable action-potential firing and was thus added to the models at this stage (Table 6). Transient 
A

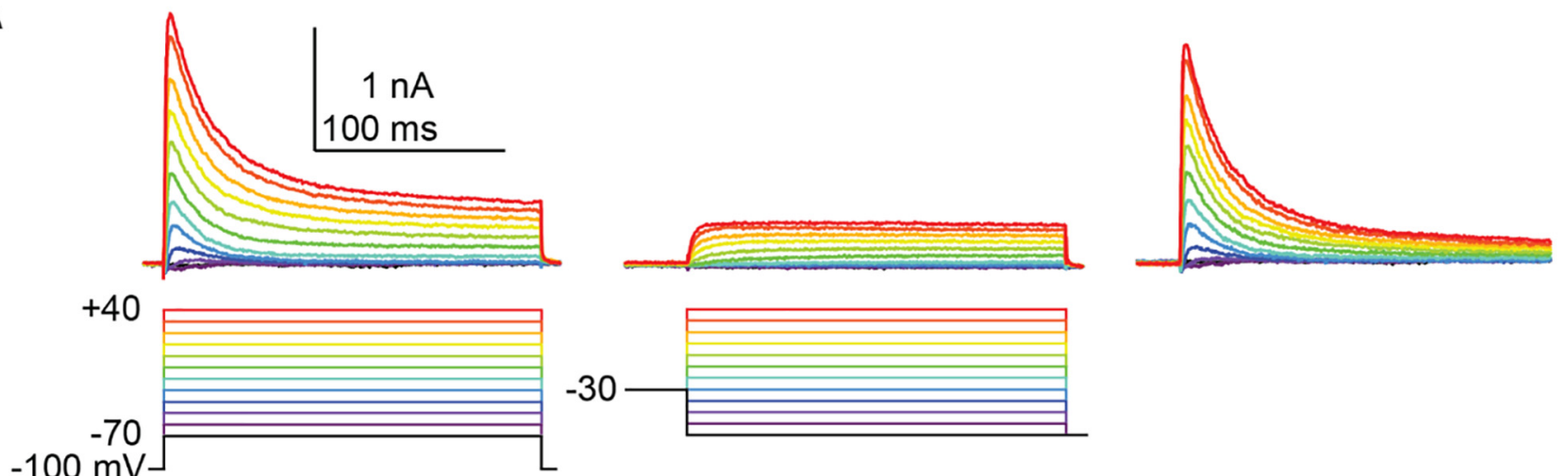

B

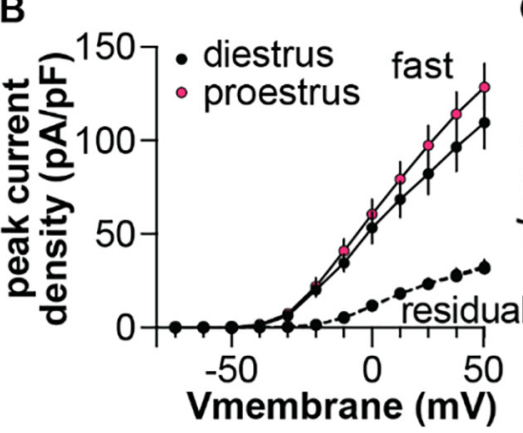

C

E

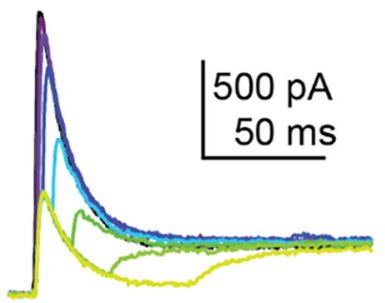

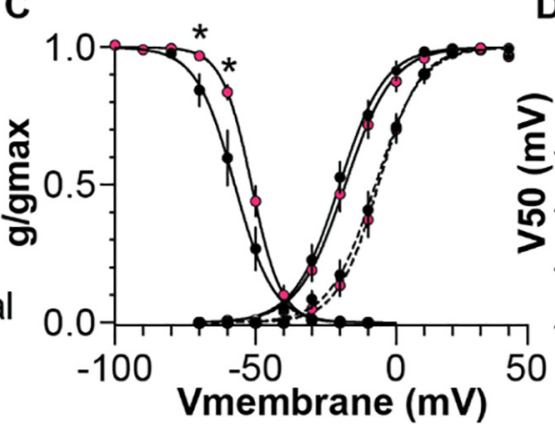

$\mathbf{F}$

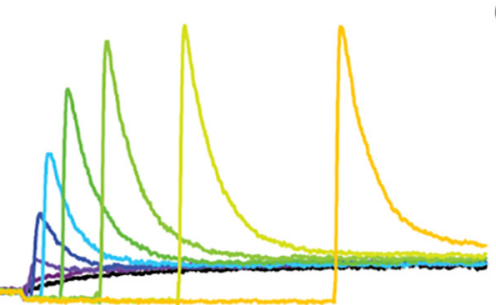

0 $-100 \mathrm{mV}$

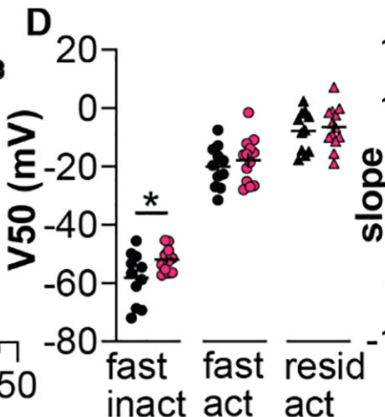

inact act act

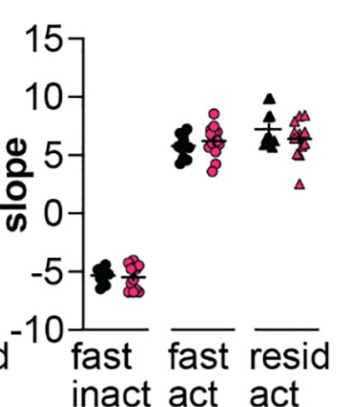

G

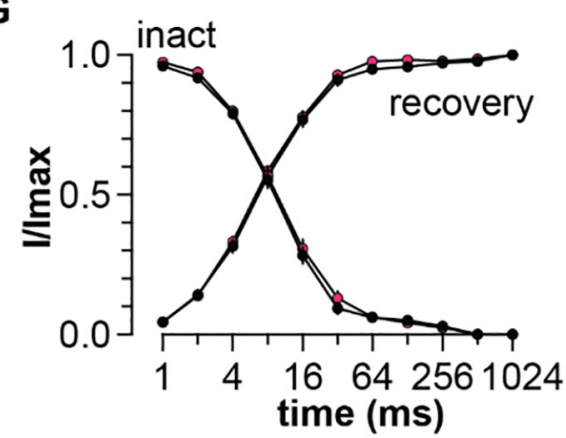

Figure 4. TEA-resistant fast-transient voltage-dependent $\mathrm{K}^{+}$current has a depolarized inactivation curve during proestrus. $\boldsymbol{A}$, left, Representative unsubtracted $\mathrm{K}^{+}$current (top) in response to the voltage-clamp protocol (bottom) in presence of 20 mM TEA. Middle, Residual current in the same cell with a $-30-\mathrm{mV}$ prepulse. Right, Fast transient current yielded by subtracting residual current from raw current. $\boldsymbol{B}$, Mean \pm SEM peak current density in cells from mice in diestrus (black symbols) and proestrus (magenta symbols). C, Mean \pm SEM normalized conductance. Solid lines represent Boltzmann sigmoidal fits to the mean data for the fast transient, dashed lines are the fits for the residual current. $\boldsymbol{D}$, Individual values and mean \pm SEM parameters obtained from Boltzmann fits to normalized conductance curves for each cell. $\boldsymbol{E}, \boldsymbol{F}$, Representative traces (top) in response to the voltage-clamp protocol (bottom) used to measure the time dependence of inactivation $(\boldsymbol{E})$ and recovery $(\boldsymbol{F})$. $\boldsymbol{G}$, Mean \pm SEM normalized peak current versus prepulse duration for time dependence of inactivation (inact) and recovery from inactivation. Error bars are smaller than symbols for some values; ${ }^{*} p<0.05$.

sodium currents of AVPV kisspeptin neurons have not been measured. We thus estimated NaT parameters using action potential properties such as threshold and peak amplitude. NaT was kept identical between diestrus and proestrus as these action potential properties did not change with cycle stage previously (Wang et al., 2016) or in this study (threshold: diestrus $-51.8 \pm 1.0 \mathrm{mV}, n=12$ cells from 5 animals, proestrus $-51.6 \pm 0.6 \mathrm{mV}, n=17$ cells from 6 animals, two-tailed, unpaired Student's $t$ test, $p=0.85, t=0.1906$, df $=27$, amplitude diestrus $82.1 \pm 1.9 \mathrm{mV}, n=12$, proestrus $80.5 \pm 1.1 \mathrm{mV}$, $n=17$, two-tailed unpaired Student's $t$ test, $p=0.4501$, $t=0.72, \mathrm{df}=22)$, suggesting estrous cycle modulation of this conductance is minimal. Using the same NaT conductance in the diestrous and proestrous models generated action potential shapes similar to experimental action potentials (Fig. 8 C). The diestrous and proestrous models were tested with the same current injection protocols used in recordings and demonstrated F-I curves similar to the mean \pm SEM data, indicating that the models could reproduce the firing behavior of AVPV kisspeptin neurons recorded in brain slices (Fig. 8D).

These models also faithfully reproduced cycle-dependent differences in posthyperpolarization rebound firing behavior observed (Wang et al., 2016). Specifically, cessation of hyperpolarization initiated rebound spikes in the 
A
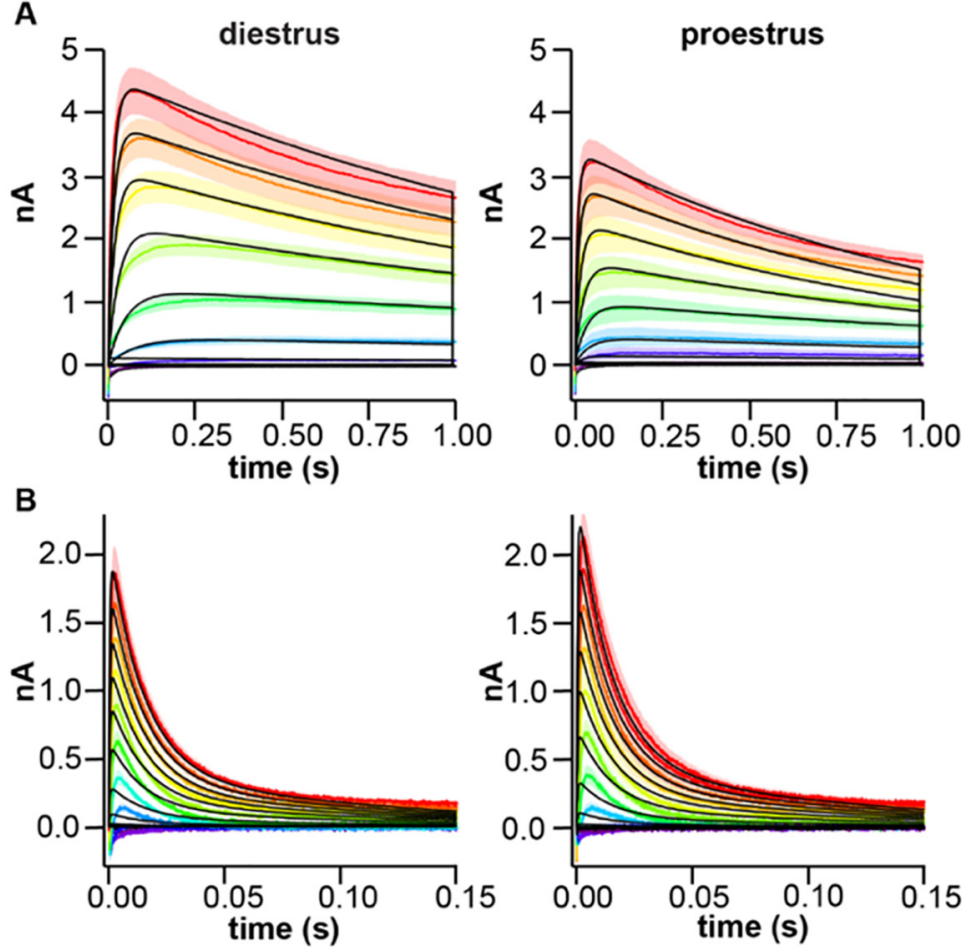

C
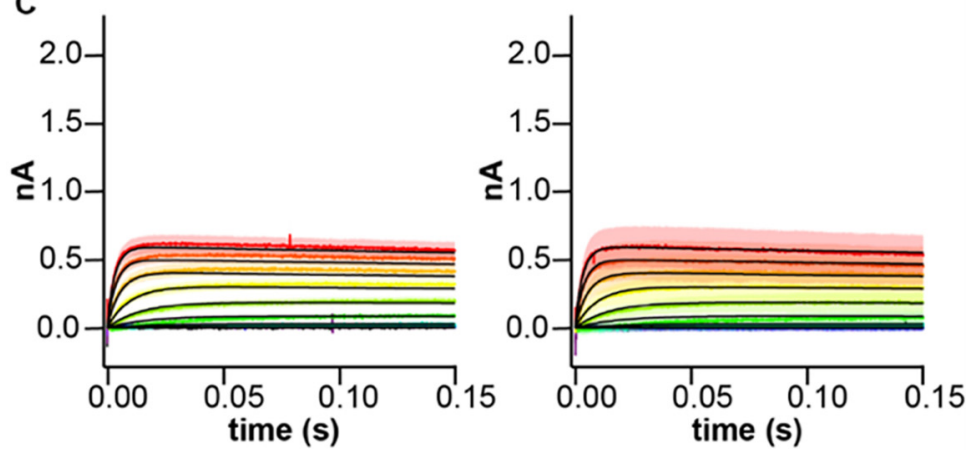

Figure 5. Potassium conductance model output versus experimental data for voltage steps. Rainbow colors indicate mean \pm SEM current traces recorded at different test potentials; black lines show model simulations. In each panel, diestrus is on the left and proestrus on the right. $\boldsymbol{A}$, Slow (voltage protocol as in Fig. 3A). B, Fast (voltage protocol as in Fig. 4A). C, Residual (voltage protocol as in Fig. 4A).

proestrous but not the diestrous model (Fig. 8B). To determine the basis for this difference as well as to further understand how each conductance influences firing behavior, we performed a series of simulations involving swapping individual or multiple conductances from one model into the other. In the diestrous model, replacing all $\mathrm{K}^{+}$conductances with their proestrus counterparts had a suppressive effect, depolarizing the rheobase and reducing the number of spikes fired in response to all depolarizing stimuli (Fig. 8E). Of the three potassium current subcomponents, proestrous $I_{\text {slow }}$ was the most suppressive when individually substituted into the diestrous model (Fig. 8E). The diestrous model with only $\mathrm{l}_{\text {fast }}$ substituted for the proestrous counterpart had a depolarized rheobase but the F-I curve (Fig. $8 E$ ) had a similar slope. Changing from diestrous to proestrus $I_{\text {residual }}$ did not change firing behavior (Fig. 8E), consistent with this current being similar between groups (Fig. 4). Of the subthreshold depolarizing conductances, proestrous $\mathrm{CaT}$ caused the greatest increase in excitability when substituted into the diestrous model, generating more spikes at every depolarizing stimulus after rheobase was achieved, but not changing rheobase itself (Fig. 8F). Rebound firing only occurred in the diestrous model when all three subthreshold depolarizing currents were replaced with their proestrous counterparts (Fig. 8F,G). This model, which had diestrous $\mathrm{K}^{+}$conductances and proestrus $\mathrm{CaT}, \mathrm{NaP}$, and $\mathrm{h}$-current, had the greatest excitability of any model tested. It is important to point out that changes in excitability were not attributable to differences in either baseline membrane potential or Rinput as these were the same among models. Comparing this hybrid model to the proestrus-only model thus further indicates the suppressive effect of proestrous $\mathrm{K}^{+}$currents. 
A
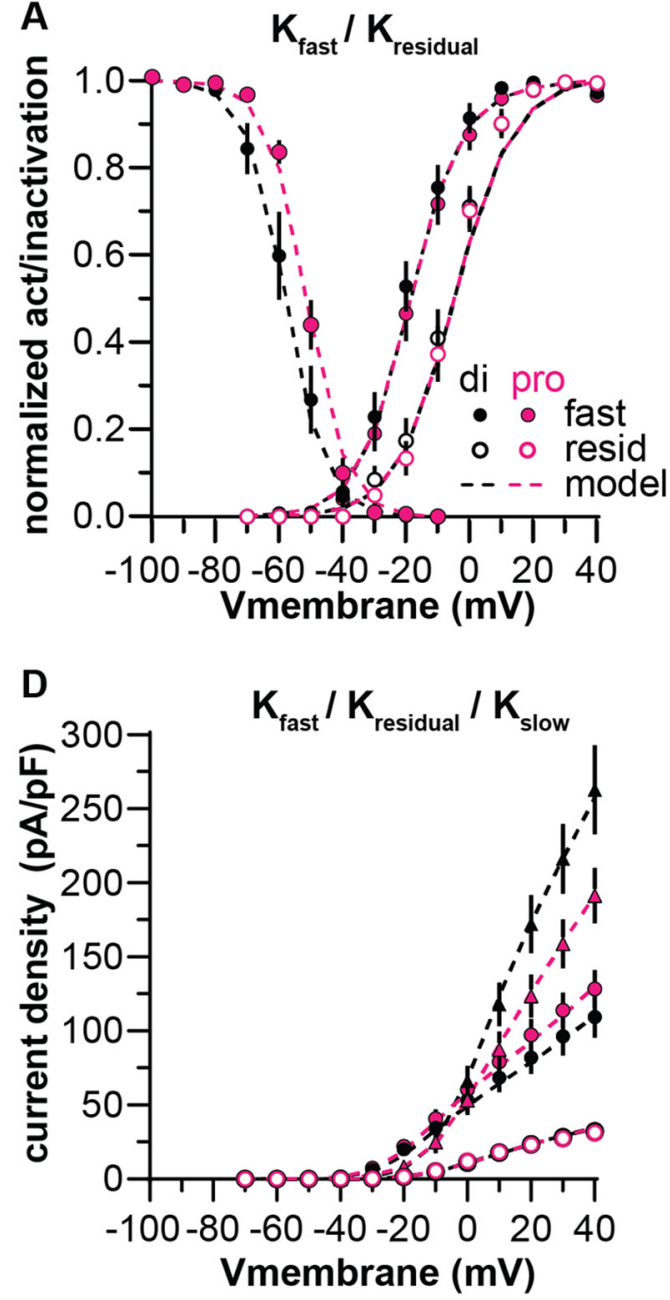

B

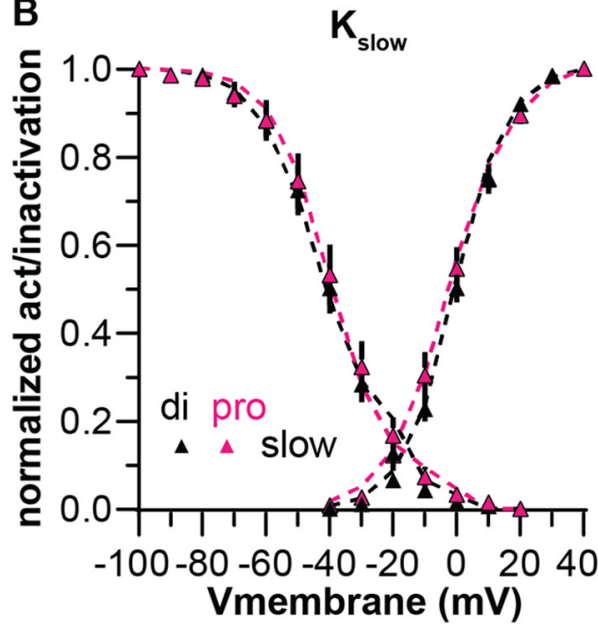

E

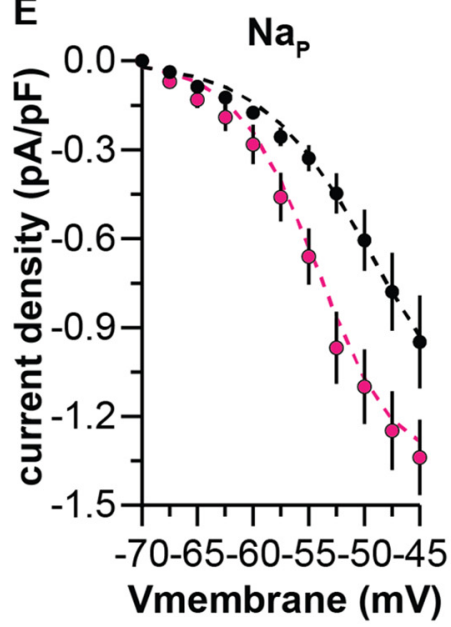

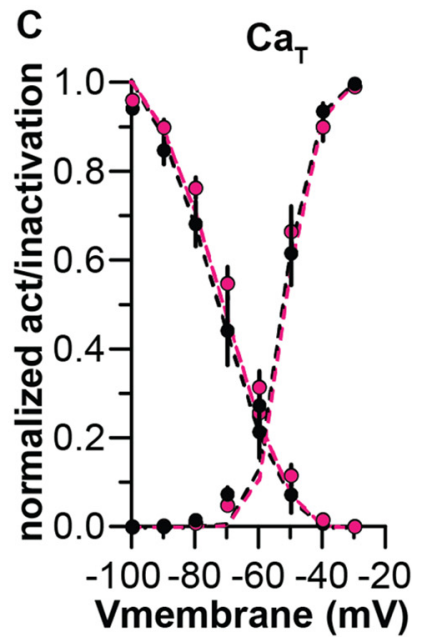

F

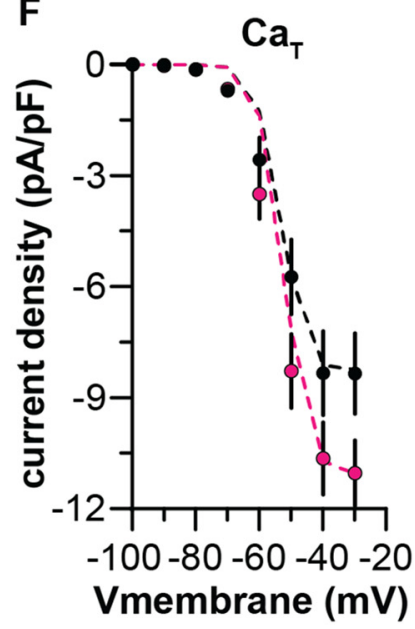

Figure 6. Conductance models versus data for steady state activation/inactivation and current density experimental data. $\boldsymbol{A}-\boldsymbol{C}$, Steady state activation/inactivation curves calculated from voltage-clamp simulations (dashed lines) compared with corresponding mean \pm SEM experimental data (symbols) from diestrous (black) and proestrous (magenta) groups. $\boldsymbol{D}-\boldsymbol{F}$, Peak current density for various conductances. Experimental data for $\mathrm{K}^{+}$current subcomponents are the same as in Figures 3, 4 and replotted here for ease of comparison. Data points for $\operatorname{NaP}(\boldsymbol{E})$ and $\mathrm{CaT}(\boldsymbol{C}, \boldsymbol{F})$ are adapted from Wang et al. (2016).

\section{Discussion}

AVPV kisspeptin-expressing neurons are key mediators of estradiol positive feedback, a process critical for ovulation. We studied intrinsic properties of these neurons to determine how they become more active during proestrus, the phase of the rodent estrous cycle when positive feedback culminates in the ovulation-inducing $\mathrm{GnRH} / \mathrm{LH}$ surges. AVPV kisspeptin neurons exhibit three types of voltage-gated potassium currents; two were modulated in an estrous-cycle dependent manner. Unexpectedly, effects of the proestrous $\mathrm{K}^{+}$currents were suppressive but countered by cycle-dependent shifts in inward currents active in the subthreshold range. The proestrous shift in $\mathrm{K}^{+}$currents did not, however, block increased rebound firing enabled by the proestrous shift in inward currents.

This finding that the $\mathrm{K}^{+}$currents on proestrus were suppressive was initially surprising given substantial evidence indicating AVPV kisspeptin neurons are activated during estradiol positive feedback (Zhang et al., 2015; Wang et al., 2016, 2019). Much of this evidence was gathered using experimental models of estradiol feedback involving ovariectomy plus estradiol replacement $(\mathrm{OVX}+\mathrm{E})$ as a constantrelease implant producing daily surges (Christian et al., 2005), or an implant followed several days later by an estradiol benzoate injection that triggers an LH surge the next day (Bronson and Vom Saal, 1979). These models allow study of estradiol feedback in isolation of other ovarian factors. In both models, AVPV kisspeptin neurons have increased c-fos expression during the LH surge (Adachi et al., 2007; Porteous and Herbison, 2019). Increases in spontaneous firing rate during positive feedback in the daily surge model are similar to those observed in naturally cycling animals on proestrus (Wang et al., 2016, 2019). Interestingly, given the changes in spontaneous firing, no studies have reported that feedback or estrous cycle stage affect the F-I curve of AVPV kisspeptin neurons. Our data and simulations suggest this lack of effect on the F-I curve is attributable to more suppressive $\mathrm{K}^{+}$currents during 
Table 4: Model parameters for diestrus

\begin{tabular}{|c|c|c|c|c|c|c|c|c|c|c|c|c|}
\hline & Slow & & Fast & & Residua & & $\mathrm{NaP}$ & & $\mathrm{CaT}$ & & $\mathrm{h}$ & Leak \\
\hline$\overline{E(m V)}$ & -92.00 & & -92.00 & & -92.00 & & 50.00 & & 155.00 & & -19.90 & $\overline{-70.00}$ \\
\hline $\bar{g}(\mathrm{nS})$ & 37.4 & & 36.9 & & 29.7 & & 0.14 & & 1.60 & & 0.11 & 1.06 \\
\hline & $\mathrm{m}$ & $\mathrm{h}$ & $\mathrm{m}$ & h & $\mathrm{m}$ & $\mathrm{h}$ & $\mathrm{m}$ & h & $\mathrm{m}$ & $\mathrm{h}$ & $\mathrm{m}$ & \\
\hline$V_{50}$ & -1.70 & -43.84 & -19.22 & -57.95 & -5.54 & -39.16 & 50.45 & 31.84 & -55.61 & -76.02 & -97.55 & \\
\hline $\mathrm{K}$ & -7.73 & 8.41 & -7.84 & $\begin{array}{l}6.33 \\
h 1=14.55 \\
h 2=113.55\end{array}$ & -8.85 & 11.29 & -3.72 & 3.20 & -5.45 & 10.90 & 4.19 & \\
\hline tau & Eq. 8 & Eq. 8 & Eq. 9 & & Eq. 8 & Eq. 8 & 0.40 & Eq. 10 & Eq. 9 & Eq. 9 & Eq. 9 & \\
\hline va & 1.40 & 64.50 & 0.53 & & 0.93 & 64.50 & & 67.30 & 1.85 & 15.58 & 201.00 & \\
\hline b & 1.54 & 1401.00 & 0.00 & & 16.39 & 1401.65 & & -27.50 & 1.65 & 70.15 & 0.00 & \\
\hline c & 15.81 & 59.70 & -8.68 & & 44.02 & 59.77 & & 67.30 & -60.60 & -57.66 & -2.20 & \\
\hline d & -0.27 & -6.42 & 7.88 & & -0.33 & -6.42 & & 27.50 & 5.00 & 3.61 & -5.95 & \\
\hline e & 8.67 & 1.34 & & & 0.13 & 1.34 & & 4650.15 & & & & \\
\hline$f$ & 2.89 & -8.26 & & & -6.77 & -8.26 & & 62.48 & & & & \\
\hline g & 8.50 & 1.82 & & & 7.76 & 1.82 & & & & & & \\
\hline$r$ & & & & & & & & 1 & & 2 & 1 & $\mathrm{n} / \mathrm{a}$ \\
\hline
\end{tabular}

proestrus counteracting larger inward currents during depolarization, without inhibiting rebound burst firing.

Estradiol feedback also affects voltage-gated $\mathrm{K}^{+}$currents in other central neurons controlling reproduction. In $\mathrm{GnRH}$ neurons, inactivation of the transient $\mathrm{K}^{+}$current is depolarized by positive feedback in the daily surge model to a similar degree observed in the present study (DeFazio et al., 2002). In contrast to AVPV neurons, however, peak $\mathrm{K}^{+}$current densities in $\mathrm{GnRH}$ neurons are reduced during positive feedback, and excitability is increased (Adams et al., 2018). Interestingly, positive feedback effects in $\mathrm{GnRH}$ neurons may be at least in part attributable to increased kisspeptin receptor activation, as kisspeptin treatment has similar effects on transient $\mathrm{K}^{+}$currents in these cells (Pielecka-Fortuna et al., 2011). In arcuate kisspeptin neurons, $\mathrm{K}^{+}$currents were compared between open-loop (OVX) and estradiol negative feedback (DeFazio et al., 2019), with negative feedback reducing peak transient and sustained $\mathrm{K}^{+}$currents compared with open-loop but not affecting voltage sensitivity of activation/inactivation. Together these observations suggest the effects of estradiol and cycle stage on voltage-gated $\mathrm{K}^{+}$currents in the reproductive neuroendocrine circuitry depend on both cell type and type of feedback involved.

The subcellular mechanisms linking estradiol feedback to these effects have not been extensively studied but may include changes in channel subunit expression/composition, subcellular location of channels, binding by partner proteins, and/or subunit phosphorylation state (Coetzee et al., 1999; Levitan, 2006). In GnRH neurons, estradiol or cycle stage regulates expression of $\mathrm{Ca}^{2+}$, HCN, and SK channel genes (Zhang et al., 2009; Bosch et al., 2013; Rønnekleiv et al., 2015; Vastagh et al., 2019). K ${ }^{+}$ channel genes are also estradiol-sensitive in the paraventricular and arcuate nuclei (Qiu et al., 2006; Roepke et al., 2007; Lee et al., 2013; Yang et al., 2016). Estradiol affects transcription of ion channels outside the central nervous system in neural (Du et al., 2014) and non-neural tissue (Marni et al., 2009; Banciu et al., 2018). In addition to transcription, estradiol action through membrane-associated signaling pathways can rapidly modulate L-type and Rtype $\mathrm{Ca}^{2+}$ and K-ATP currents (Sun et al., 2010; Zhang et

Table 5: Model parameters for proestrus

\begin{tabular}{|c|c|c|c|c|c|c|c|c|c|c|c|c|}
\hline \multirow{4}{*}{$\begin{array}{l} \\
\mathrm{E}(\mathrm{mV}) \\
\bar{g}(\mathrm{nS})\end{array}$} & \multicolumn{2}{|l|}{ Slow } & \multicolumn{2}{|l|}{ Fast } & \multicolumn{2}{|c|}{ Residual } & \multicolumn{2}{|l|}{$\mathrm{NaP}$} & \multicolumn{2}{|l|}{ CaT } & $\mathrm{h}$ & \multirow{2}{*}{$\frac{\text { Leak }}{-70.00}$} \\
\hline & -92.00 & & -92.00 & & -92.00 & & 50.00 & & 155.00 & & -19.90 & \\
\hline & 42.0 & & 45.7 & & 32.9 & & 0.20 & & 2.0 & & 0.64 & 0.88 \\
\hline & $\mathrm{m}$ & $\mathrm{h}$ & $\mathrm{m}$ & h & $\mathrm{m}$ & $\mathrm{h}$ & $\mathrm{m}$ & $\mathrm{h}$ & $\mathrm{m}$ & $\mathrm{h}$ & $\mathrm{m}$ & \\
\hline$V_{50}$ & -3.71 & -40.51 & -19.22 & -57.13 & -5.54 & -39.16 & 50.45 & 31.84 & -54.87 & -74.00 & -97.55 & \\
\hline $\mathrm{K}$ & -9.01 & 8.41 & -7.84 & $\begin{array}{l}6.33 \\
h 1=14.55 \\
h 2=113.55\end{array}$ & -8.85 & 11.29 & -3.72 & 3.20 & -5.45 & 10.90 & 4.19 & \\
\hline tau & Eq. 8 & Eq. 8 & Eq. 9 & & Eq. 8 & Eq. 8 & 0.40 & Eq. 10 & Eq. 9 & Eq. 9 & Eq. 9 & \\
\hline a & 1.40 & 64.50 & 0.47 & & 0.93 & 64.50 & & 67.30 & 1.85 & 15.58 & 201.00 & \\
\hline b & 0.66 & 873.09 & 0.00 & & 16.39 & 1401.65 & & -27.50 & 1.65 & 70.15 & 0.00 & \\
\hline c & 20.02 & 46.89 & -8.68 & & 44.02 & 59.77 & & 67.30 & -60.60 & -57.50 & -2.20 & \\
\hline d & -0.20 & -6.42 & 7.88 & & -0.33 & -6.42 & & 27.50 & 5.00 & 3.61 & -5.95 & \\
\hline e & 8.67 & 1.34 & & & 0.13 & 1.34 & & 3980.90 & & & & \\
\hline$f$ & -8.10 & -8.26 & & & -6.77 & -8.26 & & 62.48 & & & & \\
\hline g & 10.50 & 1.82 & & & 7.76 & 1.82 & & & & & & \\
\hline$r$ & & & & & & & & 1 & & 2 & 1 & \\
\hline
\end{tabular}



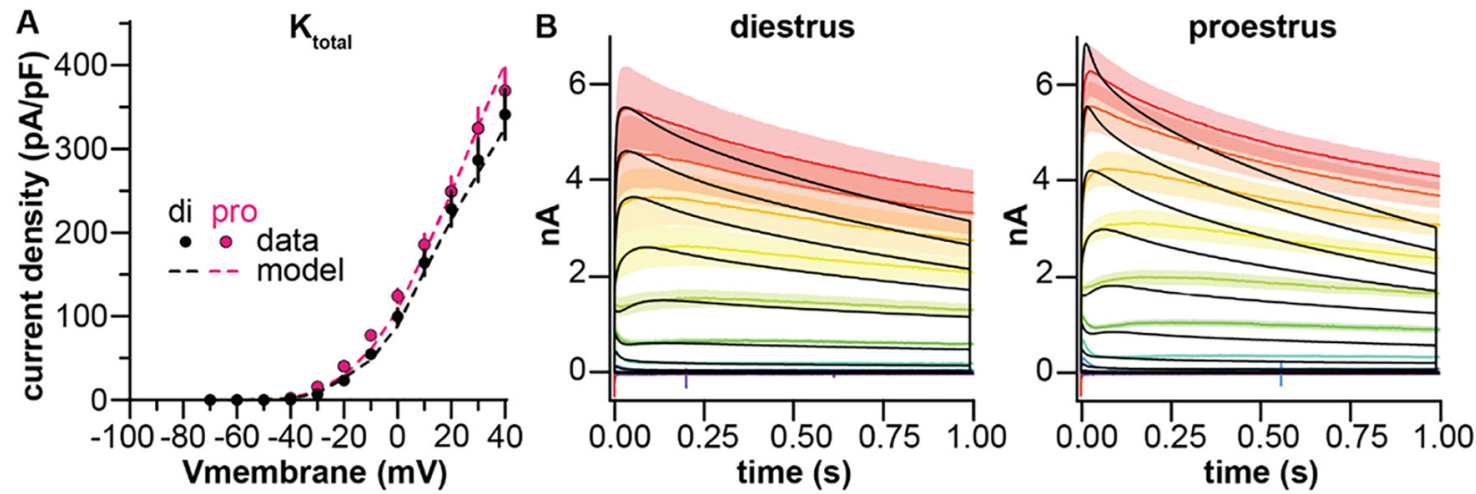

Figure 7. Reconstruction of the total $\mathrm{K}^{+}$current from the sum of the three subcomponents. $\boldsymbol{A}$, Peak current density when $\mathrm{I}_{\text {fast }}$, $\mathrm{I}_{\text {slow, }}$ and $\mathrm{I}_{\text {resid }}$ are simulated together in the same model (dashed lines) after $\bar{g}$ optimization to correct for suppression by TEA/4-AP. Mean \pm SEM symbols (black: diestrus, magenta: proestrus) and voltage-clamp protocols are the same as shown in Figure $1 A, D$ and are reproduced for ease of comparison. $\boldsymbol{B}$, Mean \pm SEM experimental current traces at different test pulses (rainbow colors) and model simulation (black).

al., 2010). Estradiol positive feedback effects on $\mathrm{K}^{+}$ currents in GnRH neurons are attenuated by a broadspectrum kinase inhibitor, suggesting a role of phosphorylation (DeFazio and Moenter, 2002). Estradiol may also interact directly with channels, as with voltage-gated BK channels in vascular smooth muscle (Granados et al., 2019). Effects of estradiol on CaT currents in AVPV kisspeptin neurons, however, are dependent on actions via $\mathrm{ER} \alpha$ as cre-lox or CRISPR mediated ER $\alpha$ knock-down in these cells eliminates estradiol effects (Wang et al., 2019).

The present results add important information to a growing list of voltage-gated conductances in AVPV kisspeptin neurons that are modified by the estrous cycle (Piet et al., 2013; Zhang et al., 2015; Wang et al., 2016). We used in silico approaches to amalgamate multiple experimental findings into a more comprehensive understanding of how hormonal manipulations/estrous cycle shape the membrane response of these cells as in other reproductive neuroendocrine neurons (Moran et al., 2016; Adams et al., 2018; Mendonça et al., 2018; DeFazio et al., 2019). Simulation results suggest modulation of $\mathrm{K}^{+}$currents across the negative to positive feedback transition do not increase AVPV neuron excitability or enable rebound burst firing, as had been suggested by blocking the fast-transient current with 4-AP in current-clamp studies (Wang et al., 2016). Rather, proestrous shifts in subthreshold inward currents $\mathrm{CaT}$, $\mathrm{NaP}$, and $\mathrm{HCN}$ counteract suppressive $\mathrm{K}^{+}$currents during proestrus and enable rebound firing. Involvement of the former currents in rebound firing is consistent with their role in shaping firing behavior (Lüthi and McCormick,

Table 6: NaT Parameters

\begin{tabular}{lllll}
\hline Di/Pro & NaT & & & \\
\hline E (mV) & 50.00 & & & \\
$\bar{g}(\mathrm{nS})$ & 68.12 & & $\mathbf{r 1}(\mathbf{V})$ & $\mathbf{r 3 ( \mathbf { V } )}$ \\
& $\alpha(\mathbf{V})$ & $\boldsymbol{\beta ( V )}$ & 9.52 & 12.68 \\
$\mathrm{~s}$ & 65.24 & 48.59 & -4.66 & 3.08 \\
$\mathrm{k}$ & -6.05 & 5.09 & 1.36 & 0.014 \\
$\mathrm{r}$ & 38.40 & 391.84 & & \\
\hline
\end{tabular}

1998; Bevan and Wilson, 1999; Hille, 2001; Perez-Reyes, 2003).

The finding that cycle-dependent changes in intrinsic properties lead to no net change in excitability begs the question of how increased firing rates during proestrus are maintained when receptors for fast glutamate and GABA transmission are blocked (Wang et al., 2016). First, neuromodulation via metabotropic receptors could occur, and may alter non-voltage-sensitive mechanisms, such as G-protein-coupled inward rectifying potassium (GIRK) channels (Kelly and Qiu, 2010). Second, proestrous increases in spontaneous firing rate may be because of the emergence of rebound bursting (Wang et al., 2016). The suppressive $\mathrm{K}^{+}$current changes observed on proestrus did not inhibit this process and may bestow properties to the cell that are otherwise beneficial. For example, these more suppressive $\mathrm{K}^{+}$currents may serve a protective/ homeostatic function by limiting the increase in excitability enabled by increases in depolarizing currents. An optogenetic study examining the relationship between AVPV neuron stimulation and $\mathrm{GnRH}$ neuron firing found delayed activation of $\mathrm{GnRH}$ neurons characteristic of kisspeptin receptor activation plateaus at $10 \mathrm{~Hz}$ (Piet et al., 2018), suggesting firing frequencies above this are unnecessary. Third, excitation-release coupling in AVPV neurons may be regulated by the estrous cycle. Small increases in release probability or the readily releasable pool of kisspeptin could have substantial downstream effects on $\mathrm{GnRH}$ neuron activation with only modest differences in AVPV neuron firing frequency. Of note, kisspeptin expression by these cells is increased during positive feedback (Smith et al., 2005; Gottsch et al., 2006). An important consideration for brain slice preparations is the disruption of neuronal projections that likely play a role in cycle-dependent changes. In rodents, input from the circadian clock is critical for surge induction (van der Beek, 1996); these and other afferents may be regulators of AVPV neuron activity in vivo and would not be present in the slices used (Watson et al., 1995). 
A
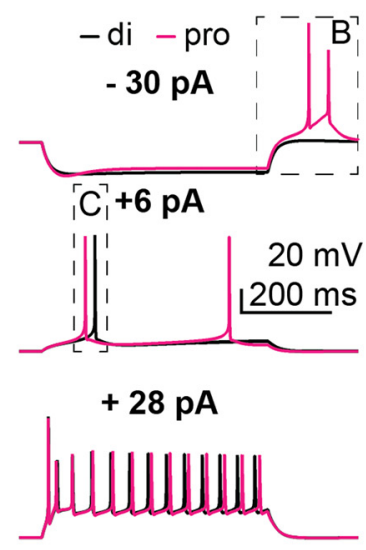

E

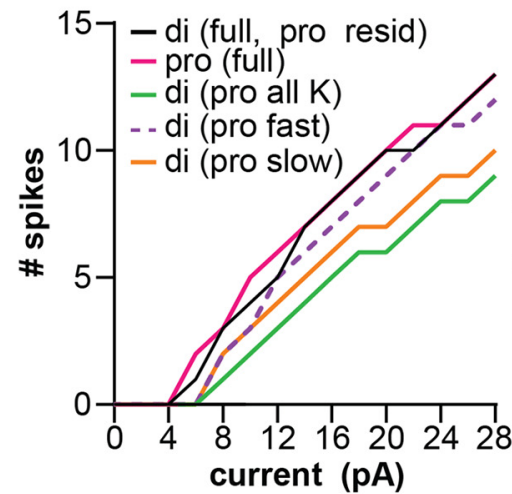

B

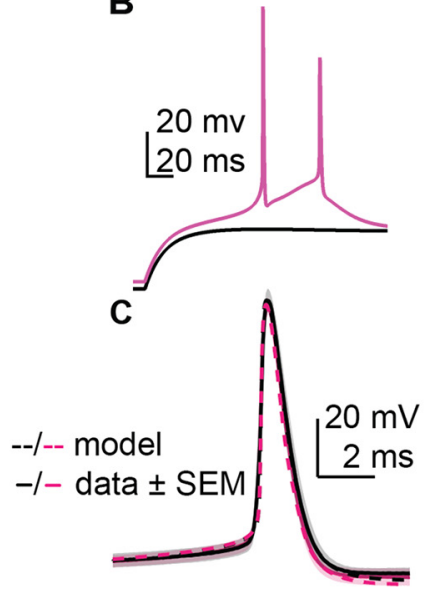

$\mathbf{F}$
D

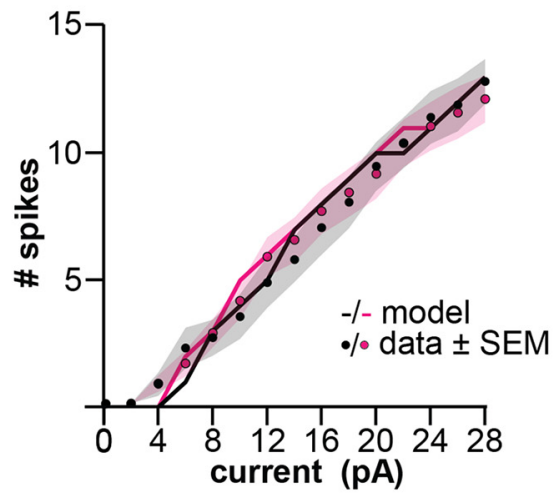

G

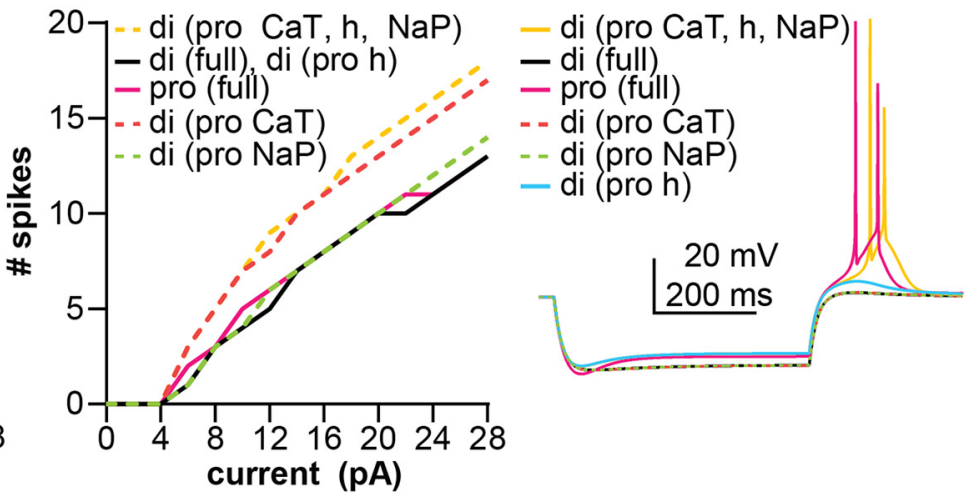

Figure 8. Simulations of firing from a baseline of $-70 \mathrm{mV}$. $\boldsymbol{A}$, Performance of diestrous (black) and proestrous (magenta) models in response to $-30 \mathrm{pA}$ (top), $+6 \mathrm{pA}$ (middle), and $+28 \mathrm{pA}$ (bottom) applied current. Boxed regions are shown with expanded axes in the indicated subfigure. $\boldsymbol{B}$, Posthyperpolarization rebound of diestrous and proestrous models from panel $\boldsymbol{A}$. $\boldsymbol{C}$, Rheobase action potentials for both models (dashed lines) from $\boldsymbol{A}$ (middle) and experimental counterparts (solid lines, mean \pm SEM). $\boldsymbol{D}, \mathrm{F}-\mathrm{I}$ curves for diestrous and proestrous models (lines) and experimental counterparts (circles are means, shading is SEM). $\boldsymbol{E}, \mathrm{F}-\mathrm{I}$ performance of hybrid models in which one or multiple $\mathrm{K}^{+}$conductances in the diestrous model was substituted for a proestrous counterpart. Non-hybrid models from part $\boldsymbol{D}$ (di full and pro full) are reproduced here to facilitate comparison in this panel as well as $\boldsymbol{F}, \boldsymbol{G}$. $\boldsymbol{F}$, F-I performance of hybrid models in which one or multiple subthreshold depolarizing currents in the diestrous model were replaced with proestrous counterparts. $\mathbf{G}$, Rebound bursting performance of hybrid models in response to $-30-p A$ current injection.

In silico approaches provide the advantage of being able to test multiple hypotheses quickly but also have several caveats. First, while we sought to make the models reasonably comprehensive by including characterizations of currents reported in the literature, there are likely uncharacterized currents expressed in AVPV neurons that may change with cycle stage and/or influence firing behavior that were not included. Second, and related to the first point, no studies have characterized the transient sodium current in AVPV neurons. We adapted a Markov model of NaT used in a GnRH neuron model to enable firing in these models (Adams et al., 2018). Estimating this current was guided by fitting the rising phase of the action potential to experimental data, the phase of the action potential most highly influenced by sodium channel properties (Kress et al., 2010). Third, no computational model is ever a perfect representation, and it is possible that other combinations of properties for the components of this model could produce similar results in firing output. Despite these limitations, our voltage-clamp models are well fit, and the firing simulations reasonably approximated the firing behavior of these cells.

Together, these results point to changes in multiple voltage-dependent currents in these cells through the reproductive cycle. Our data and firing simulations suggest estrous cycle effects on these currents are unlikely to explain the increase in AVPV kisspeptin neuron spontaneous activity during the afternoon of proestrus, as changes in typically hyperpolarizing and depolarizing currents exert reciprocal effects on excitability, though the latter contribute to the emergence of postinhibitory rebound burst firing. These findings motivate further study of the inputs controlling firing behavior of these cells as well as the mechanisms regulating their neurochemical and peptidergic output to 
GnRH neurons, and how these contribute to $\mathrm{GnRH} / \mathrm{LH}$ surge generation.

\section{References}

Adachi S, Yamada S, Takatsu Y, Matsui H, Kinoshita M, Takase K, Sugiura $\mathrm{H}$, Ohtaki T, Matsumoto $\mathrm{H}$, Uenoyama $\mathrm{Y}$, Tsukamura $\mathrm{H}$, Inoue K, Maeda K-I (2007) Involvement of anteroventral periventricular metastin/kisspeptin neurons in estrogen positive feedback action on luteinizing hormone release in female rats. J Reprod Dev 53:367-378.

Adams C, Stroberg W, DeFazio RA, Schnell S, Moenter SM (2018) Gonadotropin-releasing hormone $(\mathrm{GnRH})$ neuron excitability is regulated by estradiol feedback and kisspeptin. J Neurosci 38:1249-1263.

Armstrong CM, Bezanilla F (1977) Inactivation of the sodium channel. II. Gating current experiments. J Gen Physiol 70:567-590.

Banciu A, Banciu DD, Mustaciosu CC, Radu M, Cretoiu D, Xiao J, Cretoiu SM, Suciu N, Radu BM (2018) Beta-estradiol regulates voltage-gated calcium channels and estrogen receptors in telocytes from human myometrium. Int J Mol Sci 19:1413.

Barry PH (1994) JPCalc, a software package for calculating liquid junction potential corrections in patch-clamp, intracellular, epithelial and bilayer measurements and for correcting junction potential measurements. J Neurosci Methods 51:107-116.

Bevan MD, Wilson CJ (1999) Mechanisms underlying spontaneous oscillation and rhythmic firing in rat subthalamic neurons. J Neurosci 19:7617-7628

Bosch MA, Tonsfeldt KJ, Rønnekleiv OK (2013) mRNA expression of ion channels in $\mathrm{GnRH}$ neurons: subtype-specific regulation by $17 \beta$-estradiol. Mol Cell Endocrinol 367:85-97.

Bronson FH, Vom Saal FS (1979) Control of the preovulatory release of luteinizing hormone by steroids in the mouse. Endocrinology 104:1247-1255.

Brown-Grant K, Exley D, Naftolin F (1970) Peripheral plasma oestradiol and luteinizing hormone concentrations during the oestrous cycle of the rat. J Endocrinol 48:295-296.

Caraty A, Lomet D, Sébert ME, Guillaume D, Beltramo M, Evans NP (2013) Gonadotrophin-releasing hormone release into the hypophyseal portal blood of the ewe mirrors both pulsatile and continuous intravenous infusion of kisspeptin: an insight into kisspeptin's mechanism of action. J Neuroendocrinol 25:537-546.

Choquet D, Korn H (1992) Mechanism of 4-aminopyridine action on voltage-gated potassium channels in lymphocytes. J Gen Physiol 99:217-240.

Christian CA, Mobley JL, Moenter SM (2005) Diurnal and estradioldependent changes in gonadotropin-releasing hormone neuron firing activity. Proc Natl Acad Sci USA 102:15682-15687.

Clay JR (2000) Determining K+ channel activation curves from K+ channel currents. Eur Biophys J 29:555-557.

Clay JR (2009) Determining k channel activation curves from $k$ channel currents often requires the Goldman-Hodgkin-Katz equation. Front Cell Neurosci 3:20.

Coetzee WA, Amarillo Y, Chiu J, Chow A, Lau D, McCormack T, Moreno H, Nadal MS, Ozaita A, Pountney D, Saganich M, VegaSaenz de Miera E, Rudy B (1999) Molecular diversity of K+ channels. Ann NY Acad Sci 868:233-285.

Cravo RM, Margatho LO, Osborne-Lawrence S, Donato J, Atkin S, Bookout AL, Rovinsky S, Frazão R, Lee CE, Gautron L, Zigman JM, Elias CF (2011) Characterization of Kiss1 neurons using transgenic mouse models. Neuroscience 173:37-56.

Cropper EC, Jing J, Vilim FS, Weiss KR (2018) Peptide cotransmitters as dynamic, intrinsic modulators of network activity. Front Neural Circuits 12:78.

DeFazio RA, Moenter SM (2002) Estradiol feedback alters potassium currents and firing properties of gonadotropin-releasing hormone neurons. Mol Endocrinol 16:2255-2265.
DeFazio RA, Heger S, Ojeda SR, Moenter SM (2002) Activation of Atype gamma-aminobutyric acid receptors excites gonadotropinreleasing hormone neurons. Mol Endocrinol 16:2872-2891.

DeFazio RA, Elias CF, Moenter SM (2014) GABAergic transmission to kisspeptin neurons is differentially regulated by time of day and estradiol in female mice. J Neurosci 34:16296-16308.

DeFazio RA, Navarro MA, Adams CE, Milescu LS, Moenter SM (2019) Estradiol enhances the depolarizing response to GABA and AMPA synaptic conductances in arcuate kisspeptin neurons by diminishing voltage-gated potassium currents. J Neurosci 39:95329545.

Döcke F, Dörner G (1965) The mechanism of the induction of ovulation by oestrogens. J Endocrinol 33:491-499.

Du J, Wang Q, Hu F, Wang J, Ding H, Gao R, Xiao H, Wang L (2014) Effects of estradiol on voltage-gated potassium channels in mouse dorsal root ganglion neurons. J Membr Biol 247:541-548.

Dutton A, Dyball REJ (1979) Phasic firing enhances vasopressin release from the rat neurohypophysis. J Physiol 290:433-440.

Gold MS, Shuster MJ, Levine JD (1996) Characterization of six voltage-gated $\mathrm{K}+$ currents in adult rat sensory neurons. J Neurophysiol 75:2629-2646.

Goodman RL (1978) The site of the positive feedback action of estradiol in the rat. Endocrinology 102:151-159.

Gorur-Shandilya S, Hoyland A, Marder E (2018) Xolotl: an intuitive and approachable neuron and network simulator for research and teaching. Front Neuroinform 12:87.

Gottsch ML, Clifton DK, Steiner RA (2006) Kisspepeptin-GPR54 signaling in the neuroendocrine reproductive axis. Mol Cell Endocrinol 254-255:91-96.

Granados ST, Castillo K, Bravo-Moraga F, Sepúlveda RV, Carrasquel-Ursulaez W, Rojas M, Carmona E, Lorenzo-Ceballos Y, González-Nilo F, González C, Latorre R, Torres YP (2019) The molecular nature of the $17 \beta$-Estradiol binding site in the voltageand $\mathrm{Ca} 2+$-activated $\mathrm{K}+(\mathrm{BK})$ channel $\beta 1$ subunit. Sci Rep 9:9965.

Greep RO, Van Dyke HB, Chow BF (1942) Gonadotropins of the swine pituitary I. Various biological effects of purified Thylakentrin (FSH) and pure metakentrin (ICSH). Endocrinology 30:635-649.

Han SK, Gottsch ML, Lee KJ, Popa SM, Smith JT, Jakawich SK, Clifton DK, Steiner RA, Herbison AE (2005) Activation of gonadotropin-releasing hormone neurons by kisspeptin as a neuroendocrine switch for the onset of puberty. J Neurosci 25:11349-11356.

Hille B (2001) Ion channels of excitable membranes, Ed 3. Sunderland: Sinauer Associates.

Kalra PS, McCann SM (1975) The stimulatory effect on gonadotropin release of implants of estradiol or progesterone in certain sites in the central nervous system. Neuroendocrinology 19:289-302.

Kehl SJ (2017) A Model of the block of voltage-gated potassium Kv4.2 ionic currents by 4-aminopyridine. J Pharmacol Exp Ther 363:184-195

Kelly MJ, Qiu J (2010) Estrogen signaling in hypothalamic circuits controlling reproduction. Brain Res 1364:44-52.

Kimm T, Khaliq ZM, Bean BP (2015) Differential regulation of action potential shape and burst-frequency firing by BK and Kv2 channels in substantia nigra dopaminergic neurons. J Neurosci 35:16404-16417.

Kress GJ, Dowling MJ, Eisenman LN, Mennerick S (2010) Axonal sodium channel distribution shapes the depolarized action potential threshold of dentate granule neurons. Hippocampus 20:558-571.

Lee SK, Ryu PD, Lee SY (2013) Estrogen replacement modulates voltage-gated potassium channels in rat presympathetic paraventricular nucleus neurons. BMC Neurosci 14:134.

Levitan IB (2006) Signaling protein complexes associated with neuronal ion channels. Nat Neurosci 9:305-310.

Lüthi A, McCormick DA (1998) $\mathrm{H}$-current: properties of a neuronal and network pacemaker. Neuron 21:9-12.

Marni F, Wang Y, Morishima M, Shimaoka T, Uchino T, Zheng M, Kaku T, Ono K (2009) 17Beta-estradiol modulates expression of low-voltage-activated $\mathrm{Ca}(\mathrm{V}) 3.2 \mathrm{~T}$-type calcium channel via 
extracellularly regulated kinase pathway in cardiomyocytes. Endocrinology 150:879-888.

Mendonça PRF, Kyle V, Yeo S-H, Colledge WH, Robinson HPC (2018) Kv4.2 channel activity controls intrinsic firing dynamics of arcuate kisspeptin neurons. J Physiol 596:885-899.

Messager S, Chatzidaki EE, Ma D, Hendrick AG, Zahn D, Dixon J, Thresher RR, Malinge I, Lomet D, Carlton MBL, Colledge $\mathrm{WH}$, Caraty A, Aparicio SAJR (2005) Kisspeptin directly stimulates gonadotropin-releasing hormone release via $G$ protein-coupled receptor 54. Proc Natl Acad Sci USA 102:1761-1766.

Moenter SM, Caraty A, Locatelli A, Karsch FJ (1991) Pattern of gonadotropin-releasing hormone $(\mathrm{GnRH})$ secretion leading up to ovulation in the ewe: existence of a preovulatory $\mathrm{GnRH}$ surge. Endocrinology 129:1175-1182.

Moran S, Moenter SM, Khadra A (2016) A unified model for two modes of bursting in GnRH neurons. J Comput Neurosci 40:297315.

Oakley AE, Clifton DK, Steiner RA (2009) Kisspeptin signaling in the brain. Endocr Rev 30:713-743.

Perez-Reyes E (2003) Molecular physiology of low-voltage-activated t-type calcium channels. Physiol Rev 83:117-161.

Petersen SL, Barraclough CA (1989) Suppression of spontaneous LH surges in estrogen-treated ovariectomized rats by microimplants of antiestrogens into the preoptic brain. Brain Res 484:279289.

Petersen SL, Cheuk C, Hartman RD, Barraclough CA (1989) Medial preoptic microimplants of the antiestrogen, keoxifene, affect luteinizing hormone-releasing hormone mRNA levels, median eminence luteinizing hormone-releasing hormone concentrations and luteinizing hormone release in ovariectomized, estrogen-treated rats. J Neuroendocrinol 1:279-283.

Pielecka-Fortuna J, Chu Z, Moenter SM (2008) Kisspeptin acts directly and indirectly to increase gonadotropin-releasing hormone neuron activity and its effects are modulated by estradiol. Endocrinology 149:1979-1986.

Pielecka-Fortuna J, DeFazio RA, Moenter SM (2011) Voltage-gated potassium currents are targets of diurnal changes in estradiol feedback regulation and kisspeptin action on gonadotropin-releasing hormone neurons in mice. Biol Reprod 85:987-995.

Piet R, Boehm U, Herbison AE (2013) Estrous cycle plasticity in the hyperpolarization-activated current in is mediated by circulating $17 \beta$-estradiol in preoptic area kisspeptin neurons. J Neurosci 33:10828-10839.

Piet R, Kalil B, McLennan T, Porteous R, Czieselsky K, Herbison AE (2018) Dominant neuropeptide cotransmission in kisspeptinGABA regulation of $\mathrm{GnRH}$ neuron firing driving ovulation. J Neurosci 38:6310-6322.

Porteous R, Herbison AE (2019) Genetic deletion of Esr1 in the mouse preoptic area disrupts the LH surge and estrous cyclicity. Endocrinology 160:1821-1829.

Qiu J, Bosch MA, Jamali K, Xue C, Kelly MJ, Rønnekleiv OK (2006) Estrogen upregulates T-type calcium channels in the hypothalamus and pituitary. J Neurosci 26:11072-11082.

Roepke TA, Malyala A, Bosch MA, Kelly MJ, Rønnekleiv OK (2007) Estrogen regulation of genes important for $\mathrm{K}+$ channel signaling in the arcuate nucleus. Endocrinology 148:4937-4951.
Rønnekleiv OK, Zhang C, Bosch MA, Kelly MJ (2015) Kisspeptin and gonadotropin-releasing hormone neuronal excitability: molecular mechanisms driven by $17 \beta$-estradiol. Neuroendocrinology 102:184-193.

Sarkar DK, Chiappa SA, Fink G, Sherwood NM (1976) Gonadotropinreleasing hormone surge in pro-oestrous rats. Nature 264:461463.

Shim WS, Conaway M, Masamura S, Yue W, Wang JP, Kumar R, Santen RJ (2000) Estradiol hypersensitivity and mitogen-activated protein kinase expression in long-term estrogen deprived human breast cancer cells in vivo. Endocrinology 141:396-405.

Simerly RB (1998) Organization and regulation of sexually dimorphic neuroendocrine pathways. Behav Brain Res 92:195-203.

Smith JT, Cunningham MJ, Rissman EF, Clifton DK, Steiner RA (2005) Regulation of Kiss1 gene expression in the brain of the female mouse. Endocrinology 146:3686-3692.

Sun J, Chu Z, Moenter SM (2010) Diurnal in vivo and rapid in vitro effects of estradiol on voltage-gated calcium channels in gonadotropin-releasing hormone neurons. J Neurosci 30:3912-3923.

van der Beek EM (1996) Circadian control of reproduction in the female rat. Prog Brain Res 111:295-320.

Vastagh C, Solymosi N, Farkas I, Liposits Z (2019) Proestrus differentially regulates expression of ion channel and calcium homeostasis genes in GnRH neurons of mice. Front Mol Neurosci 12:137.

Wang L, DeFazio RA, Moenter SM (2016) Excitability and burst generation of AVPV kisspeptin neurons are regulated by the estrous cycle via multiple conductances modulated by estradiol action. eNeuro 3:ENEURO.0094-16.2016.

Wang L, Vanacker C, Burger LL, Barnes T, Shah YM, Myers MG, Moenter SM (2019) Genetic dissection of the different roles of hypothalamic kisspeptin neurons in regulating female reproduction. Elife 8:e43999.

Watson RE, Langub MC, Engle MG, Maley BE (1995) Estrogen-receptive neurons in the anteroventral periventricular nucleus are synaptic targets of the suprachiasmatic nucleus and peri-suprachiasmatic region. Brain Res 689:254-264.

Wiegand SJ, Terasawa E (1982) Discrete lesions reveal functional heterogeneity of suprachiasmatic structures in regulation of gonadotropin secretion in the female rat. Neuroendocrinology 34:395-404.

Yang JA, Mamounis KJ, Yasrebi A, Roepke TA (2016) Regulation of gene expression by $17 \beta$-estradiol in the arcuate nucleus of the mouse through ERE-dependent and ERE-independent mechanisms. Steroids 107:128-138.

Zhang C, Roepke TA, Kelly MJ, Rønnekleiv OK (2008) Kisspeptin depolarizes gonadotropin-releasing hormone neurons through activation of TRPC-like cationic channels. J Neurosci 28:4423-4434.

Zhang C, Bosch MA, Rick EA, Kelly MJ, Rønnekleiv OK (2009) 17Beta-estradiol regulation of T-type calcium channels in gonadotropin-releasing hormone neurons. J Neurosci 29:10552-10562.

Zhang C, Kelly MJ, Rønnekleiv OK (2010) $17 \beta$-estradiol rapidly increases ATP-sensitive potassium channel activity in gonadotropin-releasing hormone neurons [corrected] via a protein kinase signaling pathway. Endocrinology 151:4477-4484.

Zhang C, Bosch MA, Qiu J, Rønnekleiv OK, Kelly MJ (2015) $17 \beta$ Estradiol increases persistent $\mathrm{Na}(+)$ current and excitability of AVPV/PeN Kiss1 neurons in female mice. Mol Endocrinol 29:518527. 